Cochrane Database of Systematic Reviews

\title{
Re-feeding versus discarding gastric residuals to improve growth in preterm infants (Review)
}

Abiramalatha T, Thanigainathan S, Balakrishnan U

Abiramalatha T, Thanigainathan S, Balakrishnan U.

Re-feeding versus discarding gastric residuals to improve growth in preterm infants.

Cochrane Database of Systematic Reviews 2019, Issue 7. Art. No.: CD012940.

DOI: 10.1002/14651858.CD012940.pub2.

www.cochranelibrary.com

Re-feeding versus discarding gastric residuals to improve growth in preterm infants (Review) 
TABLE OF CONTENTS

HEADER 1

ABSTRACT

PLAIN LANGUAGE SUMMARY

SUMMARY OF FINDINGS

BACKGROUND

OBJECTIVES

METHODS

RESULTS

Figure 1.

Figure 2.

Figure 3.

Figure 4.

DISCUSSION

AUTHORS' CONCLUSIONS

ACKNOWLEDGEMENTS

REFERENCES

CHARACTERISTICS OF STUDIES

DATA AND ANALYSES

Analysis 1.1. Comparison 1 Re-feeding versus discarding gastric residual, Outcome 1 Time to regain birth weight (days). .......

Analysis 1.2. Comparison 1 Re-feeding versus discarding gastric residual, Outcome 2 Number of Infants with NEC stage 2 or 3 and/or SIP.

Analysis 1.3. Comparison 1 Re-feeding versus discarding gastric residual, Outcome 3 Time to reach full enteral feeds ( $120 \mathrm{~mL} /$ $\mathrm{kg} / \mathrm{d})$.

Analysis 1.4. Comparison 1 Re-feeding versus discarding gastric residual, Outcome 4 Number of infants with episodes of interruption of feeds $\geq 12$ hours.

Analysis 1.5. Comparison 1 Re-feeding versus discarding gastric residual, Outcome 5 Number of infants with weight $<10$ th percentile at discharge.

Analysis 1.6. Comparison 1 Re-feeding versus discarding gastric residual, Outcome 6 Number of TPN days.

Analysis 1.7. Comparison 1 Re-feeding versus discarding gastric residual, Outcome 7 Mortality before discharge.

Analysis 1.8. Comparison 1 Re-feeding versus discarding gastric residual, Outcome 8 Duration of hospital stay (days). APPENDICES

CONTRIBUTIONS OF AUTHORS

DECLARATIONS OF INTEREST

SOURCES OF SUPPORT

DIFFERENCES BETWEEN PROTOCOL AND REVIEW

INDEX TERMS 
[Intervention Review]

\section{Re-feeding versus discarding gastric residuals to improve growth in preterm infants}

Thangaraj Abiramalatha ${ }^{1}$, Sivam Thanigainathan ${ }^{2}$, Umamaheswari Balakrishnan ${ }^{1}$

1Neonatology, Sri Ramachandra Institute of Higher Education and Research, Chennai, India. ${ }^{2}$ Neonatology, Jawaharlal Institute of Postgraduate Medical Education and Research Puducherry, Puducherry, India

Contact address: Thangaraj Abiramalatha, Neonatology, Sri Ramachandra Institute of Higher Education and Research, Chennai, Tamil Nadu, India.abi_paeds@yahoo.com.

Editorial group: Cochrane Neonatal Group

Publication status and date: New, published in Issue 7, 2019.

Citation: Abiramalatha T, Thanigainathan S, Balakrishnan U. Re-feeding versus discarding gastric residuals to improve growth in preterm infants. Cochrane Database of Systematic Reviews 2019, Issue 7. Art. No.: CD012940. DOI: 10.1002/14651858.CD012940.pub2.

Copyright (c) 2019 The Cochrane Collaboration. Published by John Wiley \& Sons, Ltd.

\section{A B S T R A C T}

\section{Background}

Routine monitoring of gastric residuals in preterm infants on gavage feeds is a common practice in many neonatal intensive care units and is used to guide the initiation and advancement of feeds. No guidelines or consensus is available on whether to re-feed or discard the aspirated gastric residuals. Although re-feeding gastric residuals may replace partially digested milk, gastrointestinal enzymes, hormones, and trophic substances that aid in digestion and promote gastrointestinal motility and maturation, re-feeding abnormal residuals may result in emesis, necrotising enterocolitis, or sepsis.

\section{Objectives}

To assess the efficacy and safety of re-feeding compared to discarding gastric residuals in preterm infants. The allocation should have been started in the first week of life and should have been continued at least until the baby reached full enteral feeds. The investigator could have chosen to discard the gastric residual in the re-feeding group, if the gastric residual quality was not satisfactory. However, the criteria for discarding gastric residual should have been predefined.

To conduct subgroup analysis based on gestational age ( $\leq 27$ weeks, 28 weeks to 31 weeks, $\geq 32$ weeks), birth weight ( $<1000 \mathrm{~g}, 1000 \mathrm{~g}$ to $1499 \mathrm{~g}, \geq 1500 \mathrm{~g}$ ), type of milk (human milk or formula milk), quality of the gastric residual (fresh milk, curded milk, or bile-stained gastric residual), volume of gastric residual replaced (total volume, 50\% of the volume, volume of the next feed, or prespecified volume, irrespective of the volume of the aspirate, e.g. $2 \mathrm{~mL}, 3 \mathrm{~mL}$ ), and whether the volume of gastric residual that is re-fed is included in or excluded from the volume of the next feed (see "Subgroup analysis and investigation of heterogeneity").

\section{Search methods}

We used the standard search strategy of Cochrane Neonatal to search the Cochrane Central Register of Controlled Trials (CENTRAL; 2018, Issue 1), MEDLINE via PubMed (1966 to 19 February 2018), Embase (1980 to 19 February 2018), and the Cumulative Index to Nursing and Allied Health Literature (CINAHL) (1982 to 19 February 2018). We also searched clinical trial databases, conference proceedings, and the reference lists of retrieved articles for randomised controlled trials and quasi-randomised trials.

\section{Selection criteria}

Randomised and quasi-randomised controlled trials that compared re-feeding versus discarding gastric residuals in preterm infants. 


\section{Data collection and analysis}

Two review authors assessed trial eligibility and risk of bias and independently extracted data. We analysed treatment effects in individual trials and reported the risk ratio and risk difference for dichotomous data, and the mean difference for continuous data, with respective $95 \%$ confidence intervals. We used the GRADE approach to assess the quality of evidence.

\section{Main results}

We found one eligible trial that included 72 preterm infants. This trial was not blinded.

We are uncertain as to the effect of re-feeding gastric residual on efficacy outcomes such as time to regain birth weight (mean difference (MD) 0.40 days, $95 \%$ confidence interval ( $\mathrm{Cl})-2.89$ to 3.69 days; very low quality evidence), time to reach enteral feeds $\geq 120 \mathrm{~mL} / \mathrm{kg} / \mathrm{d}$ (MD -1.30 days, $95 \% \mathrm{Cl}-2.93$ to 0.33 days; very low quality evidence), number of infants with extrauterine growth restriction at discharge (risk ratio (RR) $1.29,95 \% \mathrm{Cl} 0.38$ to 4.34 ; very low quality evidence), duration of total parenteral nutrition (MD -0.30 days, $95 \% \mathrm{Cl}-2.07$ to 1.47 days; very low quality evidence), and length of hospital stay (MD -1.90 days, $95 \% \mathrm{Cl}-25.27$ to 21.47 days; very low quality evidence).

Similarly, we are uncertain as to the effect of re-feeding gastric residual on safety outcomes such as incidence of stage 2 or 3 necrotising enterocolitis and/or spontaneous intestinal perforation (RR $0.71,95 \% \mathrm{Cl} 0.25$ to 2.04 ; very low quality evidence), number of episodes of feed interruption lasting $\geq 12$ hours ( $R R 0.80,95 \% \mathrm{Cl} 0.42$ to 1.52 ; very low quality evidence), or mortality before discharge (RR $0.50,95 \%$ $\mathrm{Cl} 0.14$ to 1.85; low-quality evidence). We are uncertain as to the effect of re-feeding gastric residual in the subgroups of human milk-fed and formula-fed infants. We found no data on other outcomes such as linear and head growth during hospital stay, postdischarge growth, number of infants with parenteral nutrition-associated liver disease, and neurodevelopmental outcomes.

\section{Authors' conclusions}

We found only limited data from one small unblinded trial on the efficacy and safety of re-feeding gastric residuals in preterm infants. The quality of evidence was low to very low. Hence, available evidence is insufficient to support or refute re-feeding of gastric residuals in preterm infants. A large, randomised controlled trial is needed to provide data of sufficient quality and precision to inform policy and practice.

\section{PLAIN LANGUAGE SUMMARY}

\section{Re-feeding versus discarding gastric residuals to improve growth in preterm infants}

\section{Review question}

Does re-feeding stomach aspirates in preterm infants promote growth without causing feeding problems?

\section{Background}

Monitoring of stomach aspirates to diagnose feed intolerance and necrotising enterocolitis is a common practice for preterm infants on tube feeds. There is no consensus on whether to re-feed or discard the stomach aspirates. Although re-feeding the aspirates may replace partially digested milk and gastrointestinal secretions that are essential for gastrointestinal maturation, re-feeding abnormal aspirates may result in vomiting, necrotising enterocolitis, or sepsis. We have looked for evidence from clinical trials that assessed whether re-feeding stomach aspirates is beneficial or harmful in preterm infants.

\section{Study characteristics}

The thorough literature search is up-to-date as of Febraury 2018. We found only one small randomised controlled trial (with 72 preterm infant participants) that addressed this question.

\section{Key results}

We are uncertain as to whether re-feeding stomach aspirates has an effect on important outcomes such as incidence of necrotising enterocolitis, mortality before discharge, time to regain birth weight, time to reach full enteral feeds, duration of parenteral nutrition and duration of hospital stay.

\section{Quality of evidence}

Available evidence is insufficient to support or refute re-feeding of stomach aspirates in preterm infants. More trials are needed to examine whether re-feeding the stomach aspirates is beneficial or harmful in preterm infants. 


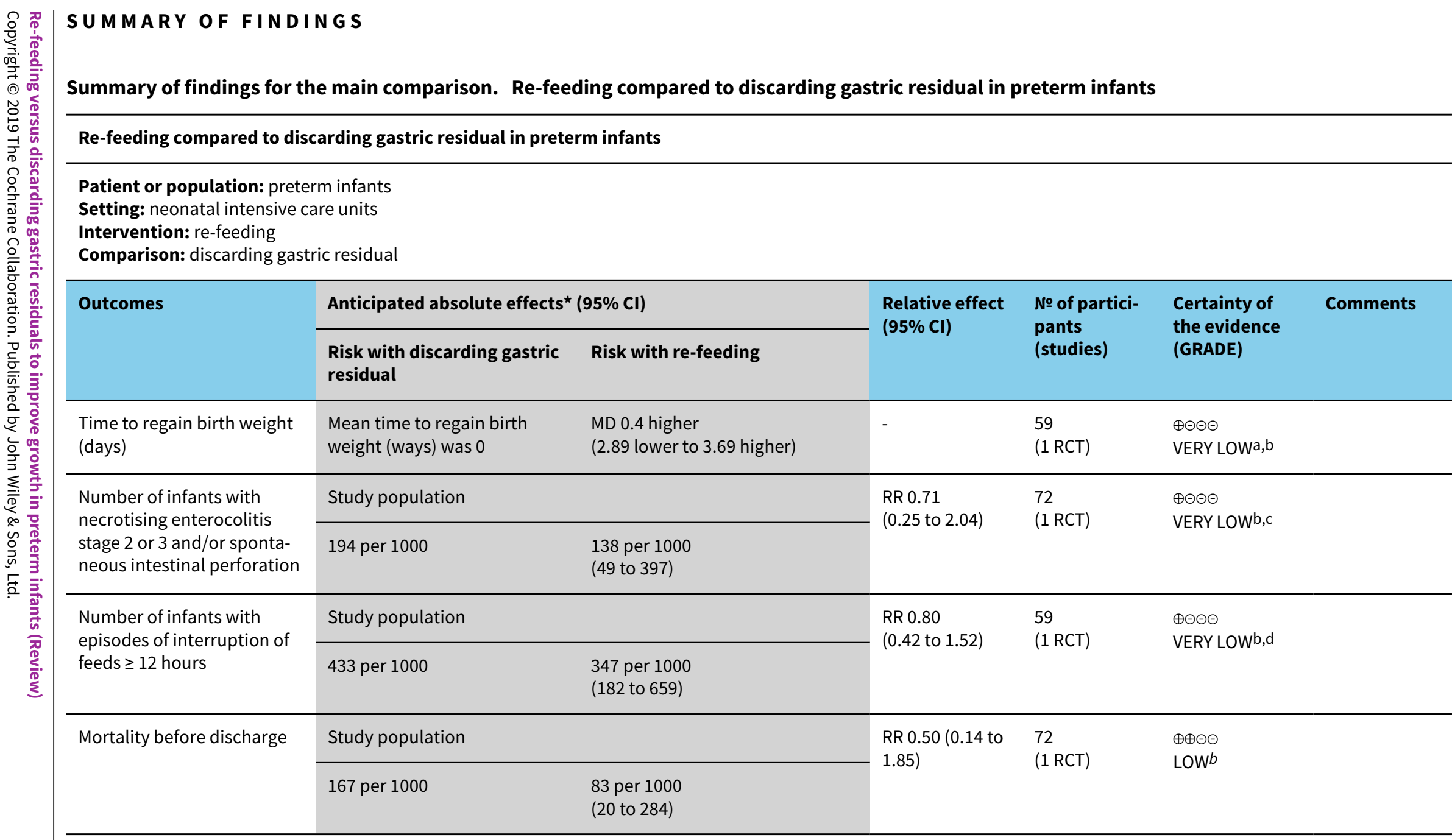

${ }^{*}$ The risk in the intervention group (and its $95 \%$ confidence interval) is based on the assumed risk in the comparison group and the relative effect of the intervention (and its $95 \% \mathrm{Cl})$.

$\mathrm{Cl}$ : confidence interval; MD: mean difference; RCT: randomised controlled trial; RR: risk ratio.

\section{GRADE Working Group grades of evidence.}

High certainty: we are very confident that the true effect lies close to that of the estimate of the effect.

Moderate certainty: we are moderately confident in the effect estimate: the true effect is likely to be close to the estimate of the effect, but there is a possibility that it is substantially different.

Low certainty: our confidence in the effect estimate is limited: the true effect may be substantially different from the estimate of the effect. 
a Concern due to attrition.

Serious Imprecision due to wide confidence interval.

cDetection bias as study authors included both NEC and SIP.

${ }^{d}$ Concern due to attrition and lack of blinding. 


\section{B A C K G R O U N D}

\section{Description of the condition}

Providing adequate nutrition is a key component of the healthcare of preterm neonates. There is increasing emphasis on early initiation and appropriate advancement of enteral feeds with the aim of achieving full-volume enteral feeds at the earliest opportunity (Dutta 2015; Stevens 2016). The major hindrance to advancing feed volumes in preterm infants is feed intolerance and the risk of necrotising enterocolitis (NEC).

Feed intolerance is a common problem in preterm infants. It causes frequent interruption and delayed advancement of enteral feeds, resulting in protracted use of total parenteral nutrition (TPN) and central venous lines (CVL), increasing the complication rate (Hermansen 2005; Duro 2011; Kaur 2015). Delay in establishing full enteral feeds is a significant contributor to growth failure in preterm infants, resulting in neurodevelopmental impairment and long-term metabolic complications (Franz 2009; Embleton 2013; Stevens 2016).

Gastric residual is the measure of volume of milk along with gastrointestinal secretions remaining in the stomach after a certain time interval. Routine monitoring of gastric residual (volume and/ or colour) in preterm infants on gavage feeds is a common practice in many neonatal intensive care units (NICUs), and is used to guide the initiation and advancement of gavage feeds (Gregory 2012). An increase in, or an altered, gastric residual is considered a sign of feed intolerance, or an early sign of NEC (Li 2014). Increased gastric residual is common in preterm infants because of many intrinsic and extrinsic factors. The intrinsic factors are related to the inherent immaturity of the gastrointestinal system in the form of delayed gastric emptying, slower intestinal transit, inadequate secretion of gut hormones and enzymes, and possible duodenogastric reflux (Ittmann 1992; Riezzo 2000). Extrinsic factors include use of formula feeds and certain drugs such as theophyllines, mydriatics, and opioids and sickness of the baby - all of which delay gastric emptying (Li 2014).

\section{Description of the intervention}

The decision on whether to re-feed or discard gastric residual in preterm infants is generally made based on the unit protocol, the physician's advice, or the nurse's experience. A small survey of neonatal nurses found that only $4 \%$ consistently replaced gastric residual after aspiration (Hodges 1993). The results of adult studies are controversial. Although one study shows a decrease in the incidence and severity of delayed gastric emptying episodes with re-feeding gastric residual (Juvé-Udina 2009), the other study shows an increase in complications such as tube clogging, diarrhoea, and nausea (Booker 2000).

For newborn infants, there are expert suggestions on the management of gastric residual based on its quantity and quality. Dutta and colleagues suggested re-feeding $50 \%$ of gastric residual or $5 \mathrm{~mL} / \mathrm{kg}$, whichever is higher, and others suggested replacing fresh or curded milk and bile-stained aspirates, but not haemorrhagic gastric residual (Dutta 2015; Salas 2015). However, Salas and colleagues showed that replacing gastric residual neither decreased the time to reach full enteral feeds nor increased the incidence of NEC in preterm infants (Salas 2015).

\section{How the intervention might work}

Gastric residual contains milk/partially digested milk and gastric secretions composed of gastric acid, enzymes, hormones, and trophic substances that aid in digestion and promote gastrointestinal motility and maturation, discarding of which may have a negative influence on the infant's gastrointestinal system (Juvé-Udina 2009; Williams 2010; Li 2014; Parker 2015). Discarding the partially digested milk and feeding the baby with fresh milk may increase the stress on the preterm gut, increasing the risk of feed intolerance. In babies who are on formula feeds, this would increase exposure to formula feeds.

Gastric acid facilitates protein and lipid digestion. Activation of pepsinogen to pepsin and protein hydrolysis require an acidic environment with a $\mathrm{pH}<4$ ( $\mathrm{Neu} 2007$ ). Gastric lipase plays an important role in lipid digestion (Neu 2007). Lingual lipase from saliva commences to act in the acidic environment of the stomach. Gastric acid, as it enters the duodenum, promotes the secretion of bile and pancreatic enzymes. Thus, discarding the gastric acid may adversely influence the digestive capacity of the preterm gut. The gastric secretions contain sodium, potassium, and chloride ions, discarding of which may result in deficiency of these ions. Gastric mucin that is protective to the mucosa and regulatory peptides such as leptin and ghrelin are also lost in the discarded gastric residual.

Moreover, the acidic environment in the stomach acts as a barrier for bacterial growth and entry into the lower gastrointestinal tract. This is shown in studies on $\mathrm{H} 2$ blockers, which cause bacterial overgrowth in the distal intestine and increase the incidence of NEC and nosocomial sepsis (Graham 2006; Guillet 2006). Manually removing the gastric acid every two to three hours may create an alkaline environment and may increase the risk of NEC and lateonset sepsis.

However, re-feeding bile- or blood-stained gastric residual might result in gastric irritation and emesis, worsening feed intolerance (Salas 2015). Returning the gastric contents after manipulation might increase the risk of infection of the preterm gut, resulting in NEC and/or sepsis (Booker 2000).

\section{Why it is important to do this review}

Given the potential benefits of re-feeding gastric residual as well as the possible risks associated with re-feeding, we undertook a systematic review to identify and appraise data from randomised controlled trials, to provide a synthesis of evidence to inform practice and research. We could not find an existing systematic review on this topic.

The question of whether routine monitoring of gastric residual improves important clinical outcomes in preterm infants is addressed in a separate review (Abiramalatha 2018).

\section{O B JECTIVES}

To assess the efficacy and safety of re-feeding compared to discarding gastric residuals in preterm infants. The allocation should have been started in the first week of life and should have been continued at least until the baby reached full enteral feeds. The investigator could have chosen to discard the gastric residual in the re-feeding group, if the gastric residual quality was not 
satisfactory. However, the criteria for discarding gastric residual should have been predefined.

To conduct subgroup analysis based on gestational age ( $\leq 27$ weeks, 28 weeks to 31 weeks, $\geq 32$ weeks), birth weight ( $<1000 \mathrm{~g}, 1000$ $\mathrm{g}$ to $1499 \mathrm{~g}, \geq 1500 \mathrm{~g}$ ), type of milk (human milk or formula milk), quality of the gastric residual (fresh milk, curded milk, or bilestained gastric residual), volume of gastric residual replaced (total volume, $50 \%$ of the volume, volume of the next feed, or prespecified volume, irrespective of the volume of the aspirate, e.g. $2 \mathrm{~mL}, 3 \mathrm{~mL}$ ), and whether the volume of gastric residual that is re-fed is included in or excluded from the volume of the next feed (Subgroup analysis and investigation of heterogeneity).

\section{METHODS}

\section{Criteria for considering studies for this review}

\section{Types of studies}

Randomised or quasi-randomised trials and cluster-randomised trials were eligible for inclusion in the review.

\section{Types of participants}

Preterm infants (<37 weeks' gestation).

\section{Types of interventions}

\section{Intervention}

Re-feeding the gastric residuals, unless the predefined quality parameters were not satisfied.

Note: The investigator could predefine the volume of gastric residual that would be re-fed, say, total volume, $50 \%$ of the volume, volume of the next feed, or a prespecified volume, irrespective of the volume of the aspirate (e.g. $2 \mathrm{~mL}, 3 \mathrm{~mL}$ ), and whether the volume of residual that was re-fed would be included in or excluded from the volume of the next feed.

\section{Comparison}

Discarding the gastric residuals, irrespective of quantity and quality.

\section{Types of outcome measures}

\section{Primary outcomes}

- Time to regain birth weight (days) and subsequent rate of weight gain $(\mathrm{g} / \mathrm{kg} / \mathrm{d})$, linear growth $(\mathrm{cm} /$ week), and increase in head circumference $(\mathrm{cm} /$ week) during the initial hospitalisation period

- Number of infants with necrotising enterocolitis (NEC) stage 2 or 3 (modified Bell's staging; Walsh 1986)

\section{Secondary outcomes}

- Time to reach full enteral feeds or $\geq 150 \mathrm{~mL} / \mathrm{kg} / \mathrm{d}$ (days)

- Episodes of interruption of feeds (lasting $\geq 12$ hours)

- Number of infants with extrauterine growth restriction at discharge (number of infants who remain below the 10th percentile for the index population for weight, length, and head circumference)

- Number of days of total parenteral nutrition (TPN)
- Number of infants with parenteral nutrition-associated liver disease

- Number of days of central venous line (CVL) usage

- Incidence of invasive infection as determined by culture of bacteria or fungus from blood, cerebrospinal fluid, or urine, or from a normally sterile body space

- All-cause mortality before discharge or up to 44 weeks' postmenstrual age

- Duration of hospital stay (days)

- Growth measures following discharge from hospital to latest follow-up

- Neurodevelopmental outcomes assessed after 12 months' corrected age: neurological evaluations; developmental scores; and classifications of disability, including auditory and visual disability. We defined neurodevelopmental impairment as the presence of one or more of the following: non-ambulant cerebral palsy; developmental quotient more than two standard deviations below the population mean; and blindness (visual acuity $<6 / 60$ ) or deafness (any hearing impairment requiring - or unimproved by - amplification)

\section{Search methods for identification of studies}

We used the criteria and standard methods of Cochrane and Cochrane Neonatal (see the Cochrane Neonatal search strategy for specialised register).

\section{Electronic searches}

We conducted a comprehensive search including the Cochrane Central Register of Controlled Trials (CENTRAL; 2018, Issue 1) in the Cochrane Library; MEDLINE via PubMed (1966 to 19 February 2018); Embase (1980 to 19 February 2018); and the Cumulative Index to Nursing and Allied Health Literature (CINAHL) (1982 to 19 February 2018), using the following search terms: (gastric residual ${ }^{\star}$ OR aspirate*), plus database-specific limiters for RCTs and neonates (see Appendix 1 for the full search strategies for each database). We did not apply language restrictions.

We searched clinical trials registries (clinicaltrials.gov; the World Health Organization's International Trials Registry and Platform; and the ISRCTN Registry) for ongoing or recently completed trials.

\section{Searching other resources}

We searched the reference lists of any articles selected for inclusion in this review to identify additional relevant articles.

We searched the proceedings of the annual meetings of the Pediatric Academic Societies (1993 to 19 February 2018), the European Society for Paediatric Research (1995 to 19 February 2018), the Royal College of Paediatrics and Child Health (2000 to present), and the Perinatal Society of Australia and New Zealand (2000 to 19 February 2018). Trials reported only as abstracts were eligible if sufficient information was available from the report, or from contact with the study authors, to fulfil the inclusion criteria.

\section{Data collection and analysis}

We used the standard methods of Cochrane Neonatal (Higgins 2017). 


\section{Selection of studies}

Two review authors (TA and ST) screened the title and abstract of all studies identified by the above search strategy and independently assessed the full-text articles for all potentially relevant trials. We excluded those studies that did not meet all inclusion criteria, and we stated the reason for exclusion. We discussed any disagreements until consensus was achieved.

We recorded the selection process in sufficient detail to complete a PRISMA flow diagram and a Characteristics of excluded studies table (Moher 2009).

\section{Data extraction and management}

Two review authors (TA and ST) extracted data independently using a data collection form to aid extraction of information on design, methodology, participants, interventions, outcomes, and treatment effects from the included study. We discussed any disagreement until we reached a consensus. If data from trial reports were insufficient, we contacted the trialists for further information.

\section{Assessment of risk of bias in included studies}

Two review authors (TA and ST) independently assessed the risk of bias (low, high, or unclear) of all included trials using the Cochrane 'Risk of bias' tool for the following domains (Higgins 2017).

- Sequence generation (selection bias).

- Allocation concealment (selection bias).

- Blinding of participants and personnel (performance bias).

- Blinding of outcome assessment (detection bias).

- Incomplete outcome data (attrition bias).

- Selective reporting (reporting bias).

- Any other bias.

Any disagreements were resolved by discussion or by a third assessor. See Appendix 2 for a more detailed description of risk of bias for each domain.

\section{Measures of treatment effect}

We analysed treatment effects in the individual trials using RevMan 2014 and reported risk ratio (RR) and risk difference (RD) for dichotomous data and mean difference (MD) for continuous data, with respective $95 \%$ confidence intervals $(\mathrm{Cls})$. We planned to determine the number needed to treat for an additional beneficial outcome (NNTB) or an additional harmful outcome (NNTH) for analyses with a statistically significant difference in the RD.

\section{Unit of analysis issues}

The unit of analysis was the participating infant in individually randomised trials. For cluster-randomised trials, we planned to undertake analysis at the level of the individual while accounting for clustering in the data using an estimate of the intracluster correlation coefficient (ICC) derived from the trial (if possible), or from another source (Higgins 2017). If ICCs from other sources were used, we planned to report this and to conduct sensitivity analyses to investigate the effect of variation in the ICC. If we identified both cluster-randomised trials and individually randomised trials, we planned to combine the results when there was little heterogeneity between study designs and few interactions between effects of the intervention, and when the choice of randomisation unit was considered unlikely.

\section{Dealing with missing data}

We requested additional data from the trialists if data on important outcomes were missing or were reported unclearly. When data were still missing, we planned to examine the impact on effect size estimates in sensitivity analyses using the 'best-worst case scenario' technique.

\section{Assessment of heterogeneity}

We examined the treatment effects of individual trials and heterogeneity between trial results by inspecting the forest plots. We calculated the $\mathrm{I}^{2}$ statistic for each RR analysis to quantify inconsistency across studies and described the percentage of variability in effect estimates that might be due to heterogeneity rather than to sampling error. We classified heterogeneity as none (< $25 \%)$; low ( $25 \%$ to $49 \%)$; moderate $(50 \%$ to $74 \%)$; or high $(\geq 75 \%)$. We explored possible causes (e.g. differences in study design, participants, interventions, or completeness of outcome assessments) if we detected moderate or high heterogeneity $\left(I^{2} \geq\right.$ $50 \%)$.

\section{Assessment of reporting biases}

We planned to examine a funnel plot for asymmetry if 10 or more trials were included in the meta-analysis.

\section{Data synthesis}

We analysed all infants randomised on an intention-to-treat basis and treatment effects in the individual trials using a fixed-effect model to combine the data. For meta-analyses of categorical outcomes, we calculated typical estimates of RR and $\mathrm{RD}$, each with $95 \% \mathrm{Cls}$; for continuous outcomes, we calculated the mean difference (MD) if outcomes were measured in the same way between trials, and standardised mean difference (SMD) to combine trials measuring the same outcome using different scales. We planned to determine the number needed to treat for an additional beneficial outcome (NNTB) or an additional harmful outcome (NNTH) for analyses with a statistically significant difference in RD. When meta-analysis was judged to be inappropriate, we planned to analyse and interpret individual trials separately.

\section{Quality of evidence}

We assessed the quality of evidence for the main comparison at the outcome level using the GRADE approach as outlined in the GRADE Handbook (Schünemann 2013).

Two review authors (TA and ST) independently assessed the quality of evidence for each of the outcomes identified as critical or important for clinical decision-making. We considered evidence from randomised controlled trials as high quality but downgraded the evidence one level for serious (or two levels for very serious) limitations based upon the following: design (risk of bias), consistency across studies, directness of the evidence, precision of estimates, and presence of publication bias. We used the GRADEpro GDT Guideline Development Tool to create a 'Summary of findings' table to report the quality of the evidence.

The GRADE approach yields an assessment of the quality of a body of evidence as one of four grades. 
- High: we are very confident that the true effect lies close to that of the estimate of the effect.

- Moderate: we are moderately confident in the effect estimate: the true effect is likely to be close to the estimate of the effect, but there is a possibility that it is substantially different.

- Low: our confidence in the effect estimate is limited: the true effect may be substantially different from the estimate of the effect.

- Very low: we have very little confidence in the effect estimate: the true effect is likely to be substantially different from the estimate of effect.

\section{Subgroup analysis and investigation of heterogeneity}

- Based on gestational age: $\leq 27$ weeks, 28 weeks to 31 weeks, $\geq$ 32 weeks

- Based on birth weight: < 1000 g, 1000 g to 1499 g, $\geq 1500$ g

- Based on type of milk: human milk or formula milk

- Based on quality of the gastric residual: fresh milk, curded milk, or bile-stained residual
- Based on volume of gastric residual replaced: total volume, $50 \%$ of the volume, volume of the next feed, or prespecified volume, irrespective of the volume of the aspirate (e.g. $2 \mathrm{~mL}, 3 \mathrm{~mL}$ )

- Based on whether the volume of gastric residual that is re-fed is included in or excluded from the volume of the next feed

\section{Sensitivity analysis}

We planned to undertake sensitivity analyses to determine if the findings were affected by including only studies of adequate methodology (low risk of bias), defined as adequate randomisation and allocation concealment, blinding of intervention and measurement, and less than $10 \%$ loss to follow-up.

\section{RE S U L T S}

\section{Description of studies}

See Characteristics of included studies, Characteristics of excluded studies, and Characteristics of ongoing studies.

\section{Results of the search}

See Figure 1. 
Figure 1. Study flow diagram.

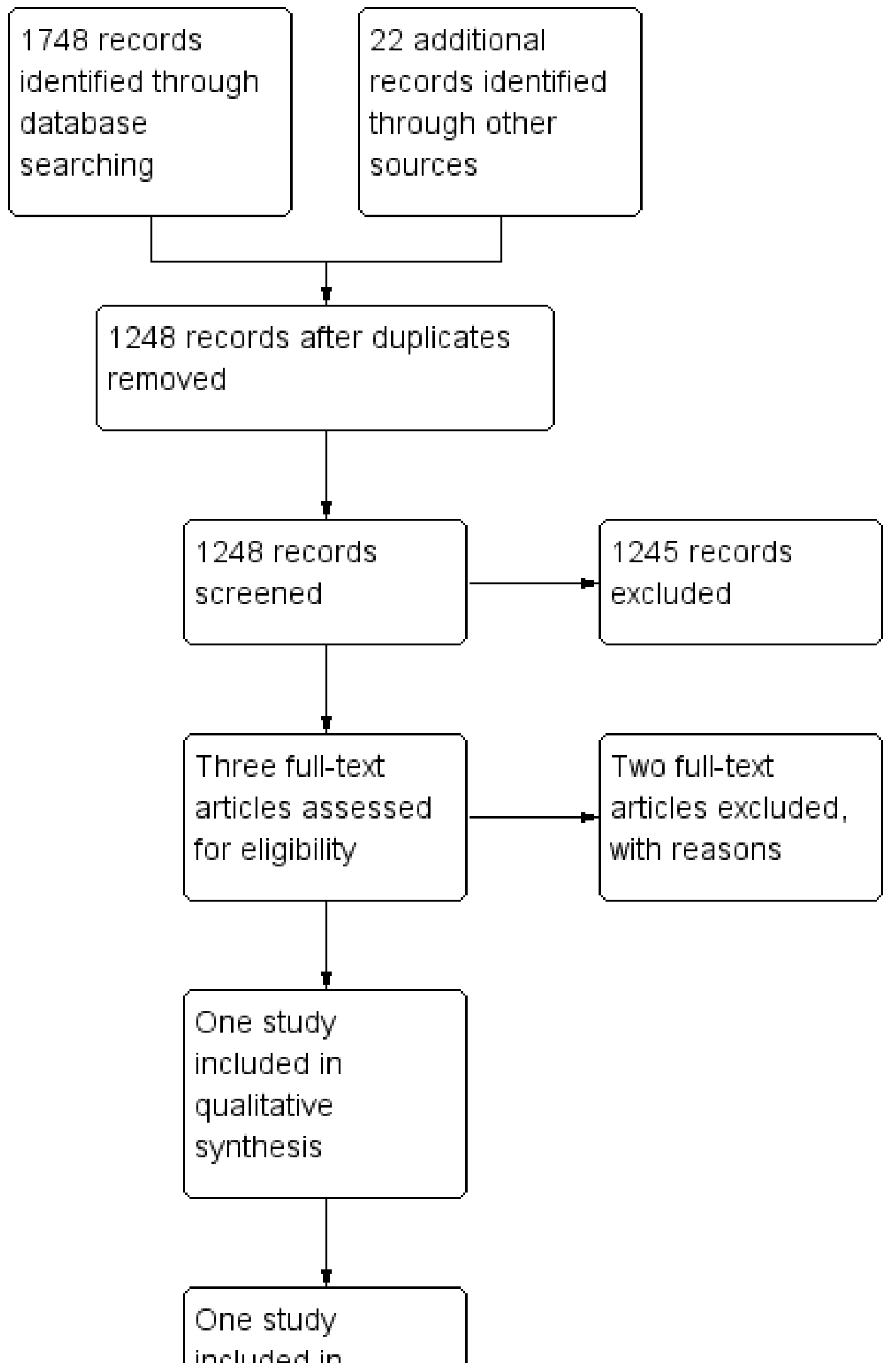


Figure 1. (Continued)

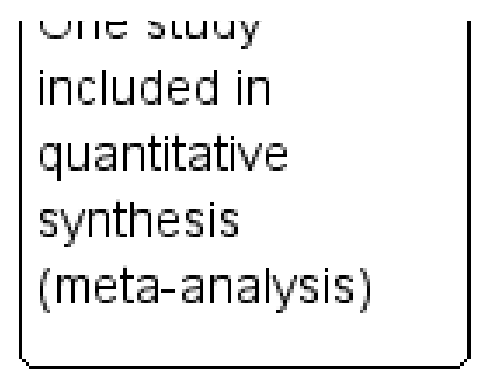

\section{Included studies}

We included one trial (Salas 2015). This trial recruited 72 infants with gestational age of 23 to 28 completed weeks who were randomised to the re-feeding or fresh-feeding group (in the freshfeeding group, gastric residual was discarded and fresh milk was fed).

Gastric residual volume was checked with a syringe before each feeding, with the infant in the supine position. If the gastric residual volume was more than one-third of the previous feeding or greater than $2 \mathrm{~mL}$, the gastric residual was re-fed in the re-feeding group, and the gastric residual was discarded followed by feeding of fresh human milk or formula in the fresh-feeding group. Small gastric residual volumes (less than one-third of previous feeding volume or $<2 \mathrm{~mL}$ ) were managed according to clinician preference (usually re-fed unless bilious or with blood).

Slightly greenish or dark yellow gastric residuals were re-fed. Gastric residuals containing blood on visual inspection by bedside nurses were not re-fed. Enteral feeding was administered as intermittent bolus gavage feedings every three hours. Either expressed human milk (preferred) from the mother or high-protein full-strength preterm formula ( $24 \mathrm{kcal} / \mathrm{oz}$ ) was used for feeding. Donor human milk was not used.

Primary outcomes were time to achieve full enteral feeding (defined as $\geq 120 \mathrm{~mL} / \mathrm{kg} / \mathrm{d}$ ) for two consecutive days and diagnosis of spontaneous intestinal perforation (SIP), NEC, and/or death between birth and 120 days or discharge (whichever was earlier). Secondary outcomes were number of TPN days, time to regain birth weight, number of episodes of feeding intolerance (defined as interruption of enteral feeding for $>12$ hours), and duration of hospital stay.

\section{Excluded studies}

We excluded two RCTs because these studies were done in adults (Characteristics of excluded studies) (Booker 2000; Juvé-Udina 2009).

\section{Risk of bias in included studies}

See Figure 2. 
Figure 2. Risk of bias summary: review authors' judgements about each risk of bias item in the included study.

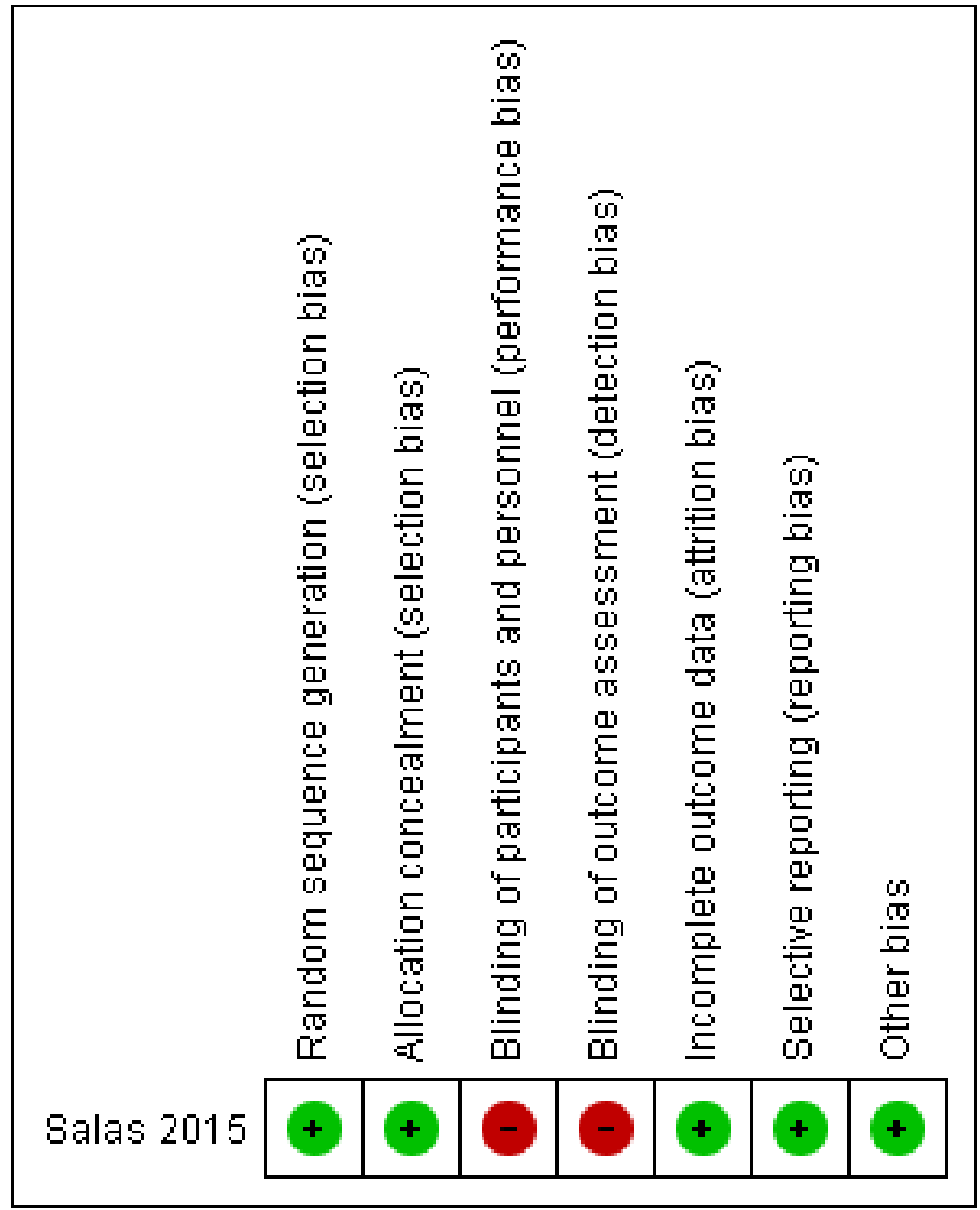

\section{Allocation}

The included trial used computer-generated random numbers for sequence generation and serially numbered sealed opaque envelopes for allocation concealment (Salas 2015).

Review authors noted the potential for selection bias and unequal exposures in the subgroup analysis of human milk versus formula milk feeding because these subgroups were not stratified at randomisation in the included trial (Salas 2015).

\section{Blinding}

The trial was unblinded; hence there is potential for performance bias and detection bias in the included trial (Salas 2015).

\section{Incomplete outcome data}

All recruited participants $(n=72)$ were accounted for in the trial.

\section{Selective reporting}

The study protocol had been published. Researchers have reported all proposed outcomes.

\section{Other potential sources of bias}

We identified no other potential sources of bias.

\section{Effects of interventions}

See: Summary of findings for the main comparison Re-feeding compared to discarding gastric residual in preterm infants

See Summary of findings for the main comparison for the main comparison re-feeding versus discarding gastric residuals in preterm infants. The quality of evidence was low to very low for all outcomes.

Re-feeding versus discarding gastric residuals: subgroup analysis by type of milk (human milk or formula milk)

\section{Time to regain birth weight}

(Analysis 1.1; Figure 3) 
Figure 3. Forest plot of comparison: 1 Re-feeding versus discarding gastric residual, outcome: 1.1 Time to regain birth weight (days).

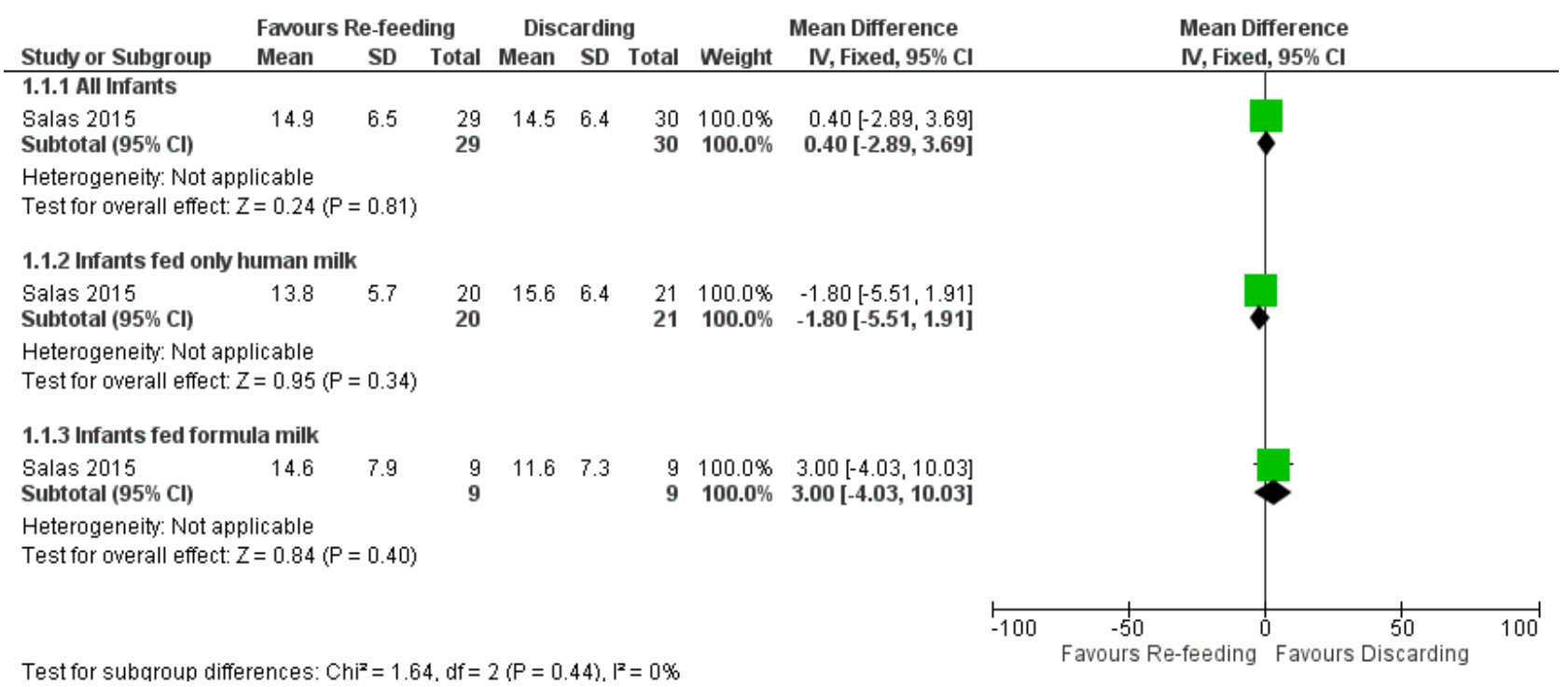

The trial did not show a difference in the time to regain birth weight between re-feeding and fresh-feeding groups (mean difference (MD) $0.40,95 \%$ confidence interval (CI) -2.89 to 3.69 days; participants $=59$; studies $=1$ ) (Salas 2015). In subgroup analyses, there was no difference in the time to regain birth weight between re-feeding and fresh-feeding groups among infants fed only human milk (MD $-1.80,95 \% \mathrm{Cl}-5.51$ to 1.91 days; participants $=41$; studies $=1$ ) and among infants fed formula milk (MD 3.00, $95 \% \mathrm{Cl}-4.03$ to
10.03 days; participants $=18$; studies $=1$ ). The trial did not report subsequent weight gain, linear growth, and head growth (Salas 2015).

Number of infants with necrotising enterocolitis (NEC) stage 2 or 3 and/or spontaneous intestinal perforation (SIP)

(Analysis 1.2; Figure 4)

Figure 4. Forest plot of comparison: 1 Re-feeding versus discarding gastric residual, outcome: 1.2 Number of Infants with NEC stage 2 or 3 and/or SIP.

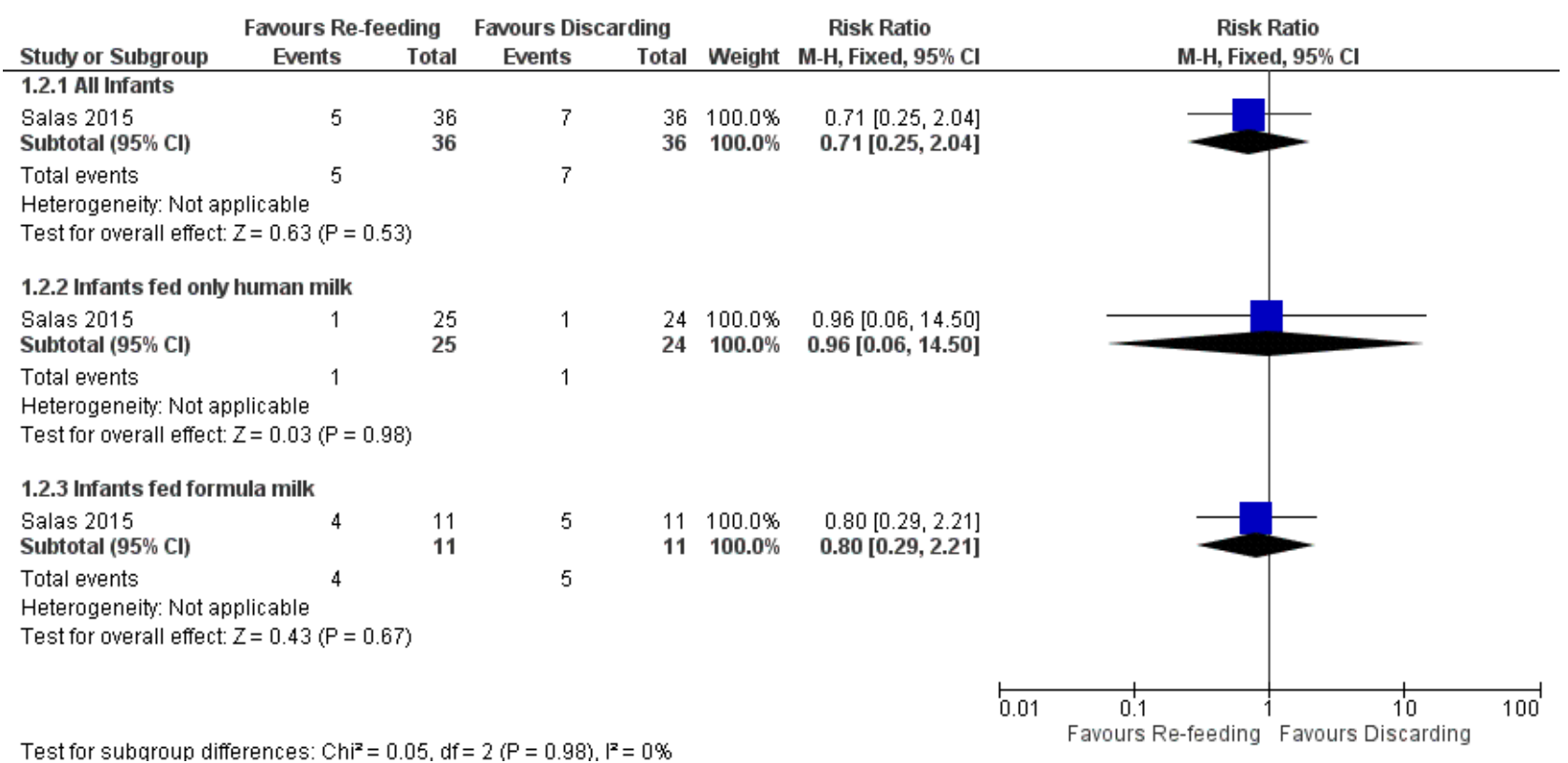

The trial did not show a difference in the incidence of stage 2 or 3 NEC and/or SIP between re-feeding and fresh-feeding groups (risk ratio (RR) $0.71,95 \% \mathrm{Cl} 0.25$ to 2.04 ; participants $=72$; studies $=1$ ) (Salas 2015). Similarly, there was no difference in the incidence of stage 2 or 3 NEC and/or SIP between groups among infants fed only human milk (RR 0.96, 95\% $\mathrm{Cl} 0.06$ to 14.50; participants $=49$; studies $=1$ ) and among infants fed formula milk (RR $0.80,95 \% \mathrm{Cl} 0.29$ to 2.21; participants $=22$; studies $=1$ ). 


\section{Time to reach full enteral feeds $(120 \mathrm{~mL} / \mathrm{kg} / \mathrm{d})$}

\section{(Analysis 1.3)}

Time to reach full feeds was defined as $\geq 120 \mathrm{~mL} / \mathrm{kg} / \mathrm{d}$ in the included trial (Salas 2015). There was no difference in the time to reach $120 \mathrm{~mL} / \mathrm{kg} / \mathrm{d}$ between re-feeding and fresh-feeding groups (MD $-1.30,95 \% \mathrm{Cl}-2.93$ to 0.33 days; participants = 59; studies $=1$ ) and no difference in outcomes among subgroups such as infants fed only human milk (MD $-0.60,95 \% \mathrm{Cl}-2.90$ to 1.70 days; participants = 41 ; studies $=1$ ) and infants fed formula milk (MD $-1.90,95 \% \mathrm{Cl}-5.50$ to 1.70 days; participants $=18$; studies $=1$ ).

\section{Number of infants with interruption of feeds (lasting $\geq 12$ hours)}

(Analysis 1.4)

The outcome was reported as the number of infants with episodes of feed interruption lasting $\geq 12$ hours in the included trial (Salas 2015). There was no difference in the outcome between intervention and control groups (RR $0.80,95 \% \mathrm{Cl} 0.42$ to 1.52 ; participants $=59$; studies $=1$ ) and no difference in the outcome between infants fed only human milk (RR 1.05, 95\% Cl 0.45 to 2.46; participants $=41$; studies $=1$ ) and infants fed formula milk (RR 0.50, $95 \% \mathrm{Cl} 0.18$ to 1.40 ; participants $=18$; studies $=1$ ).

\section{Number of infants with weight $<10$ th percentile at discharge}

(Analysis 1.5)

The trial did not report a difference in the outcome between refeeding and fresh-feeding groups in all infants (RR 1.29, 95\% $\mathrm{Cl} 0.38$ to 4.34; participants $=59$; studies $=1$ ), infants fed only human milk (RR 1.58, 95\% Cl 0.29 to 8.46; participants $=41$; studies $=1$ ), and infants fed formula milk (RR $0.50,95 \% \mathrm{Cl} 0.18$ to 1.40 ; participants = 18; studies $=1)($ Salas 2015).

\section{Number of TPN days}

(Analysis 1.6)

There was no difference in the TPN days between groups among all infants (MD $-0.30,95 \% \mathrm{Cl}-2.07$ to 1.47 days; participants = 59; studies $=1$ ), infants fed only human milk (MD $0.20,95 \% \mathrm{Cl}-2.15$ to 2.55 days; participants $=41$; studies $=1$ ), and infants fed formula milk (MD $-1.20,95 \% \mathrm{Cl}-5.04$ to 2.64 days; participants $=18$; studies $=1$ ) in the included trial (Salas 2015).

\section{Number of infants with parenteral nutrition-associated liver disease}

Trialists did not report parenteral nutrition-associated liver disease as an outcome (Salas 2015).

\section{Number of days of central venous line (CVL) usage}

Trialists did not report number of days of CVL usage as an outcome (Salas 2015).

\section{Incidence of invasive infection}

Trialists did not report incidence of invasive infection as an outcome (Salas 2015).

\section{All-cause mortality before discharge}

(Analysis 1.7)
The trial did not show a difference in all-cause mortality before discharge between re-feeding and fresh-feeding groups (RR 0.50, $95 \% \mathrm{Cl} 0.14$ to 1.85 ; participants $=72$; studies $=1$ ) $($ Salas 2015$)$. Similarly, there was no difference in the outcome between infants fed only human milk (RR $0.64,95 \% \mathrm{Cl} 0.12$ to 3.50 ; participants $=49$; studies $=1$ ) and infants fed formula milk (RR $0.33,95 \% \mathrm{Cl} 0.04$ to 2.73; participants $=22$; studies $=1$ ).

\section{Duration of hospital stay}

(Analysis 1.8)

The trials did not show a difference in duration of hospital stay between intervention and control groups (MD -1.90, 95\% Cl -25.27 to 21.47 days; participants $=59$; studies $=1$ ) (Salas 2015). There was also no difference in the outcome in subgroups such as infants fed only human milk (MD $-12.00,95 \% \mathrm{Cl}-37.97$ to 13.97 days; participants $=41$; studies $=1$ ) and infants fed formula milk (MD $51.00,95 \% \mathrm{Cl}-8.61$ to 110.61 days; participants $=18$; studies $=1$ ).

\section{Growth measures following discharge from hospital to latest follow-up}

Trialists did not report this outcome (Salas 2015).

\section{Neurodevelopmental outcomes assessed after 12 months' corrected age}

Trialists did not report this outcome (Salas 2015).

\section{Subgroup analyses}

Based on gestational age ( $\leq 27$ weeks, 28 weeks to 31 weeks, $\geq 32$ weeks): this subgroup analysis was not possible. The trial included infants between 23 and 28 completed weeks' gestational age (Salas 2015).

Based on birth weight ( $<1000 \mathrm{~g}, 1000 \mathrm{~g}$ to $1499 \mathrm{~g}, \geq 1500 \mathrm{~g}$ ): this subgroup analysis was not possible from the included trial (Salas 2015).

Based on the quality of the gastric residual - fresh milk, curded milk, or bile-stained residual: this subgroup analysis was not possible from the included trial (Salas 2015).

Based on the volume of gastric residual replaced - total volume, $50 \%$ of the volume, volume of the next feed, or prespecified volume, irrespective of the volume of the aspirate (e.g. $2 \mathrm{~mL}, 3 \mathrm{~mL}$ ): this subgroup analysis was not possible. The volume of the gastric residual replaced was equal to the volume of the next feed in all infants in the included trial (Salas 2015).

Based on whether the volume of gastric residual that is re-fed is included in or excluded from the volume of the next feed: this subgroup analysis was not possible. The volume of gastric residual replaced was included in the volume of the next feed in all infants in the included trial (Salas 2015).

\section{DISCUSSION}

\section{Summary of main results}

Only one small randomised controlled trial (RCT) with 72 preterm infants met the inclusion criteria for this Cochrane Review (Salas 2015). This trial was unblinded but otherwise of good methodological quality. 
We are uncertain as to the effect of re-feeding gastric residual on efficacy outcomes such as time to regain birth weight, time to reach enteral feeds $\geq 120 \mathrm{~mL} / \mathrm{kg} / \mathrm{d}$, number of infants with extrauterine growth restriction at discharge, duration of total parenteral nutrition, and length of hospital stay. Similarly, we are uncertain as to the effect of re-feeding gastric residual on safety outcomes such as incidence of stage 2 or 3 necrotising enterocolitis and/or spontaneous intestinal perforation, number of episodes of feed interruption lasting $\geq 12$ hours, or mortality before discharge. We found no data on other outcomes such as linear and head growth during hospital stay, postdischarge growth, number of infants with parenteral nutrition-associated liver disease, and neurodevelopmental outcomes.

In subgroup analyses, we are uncertain as to the effect of re-feeding gastric residual in human milk-fed and formula-fed infants. The quality of evidence is very low. Furthermore, there is potential for selection bias and unequal exposures between groups in this subgroup analysis because these subgroups were not stratified at randomisation in the included trial (Salas 2015).

We found no data on outcomes such as linear and head growth during hospital stay, incidence of parenteral nutrition-associated liver disease, number of central venous line (CVL) days, incidence of invasive infection, growth measures following discharge from hospital to latest follow-up, and neurodevelopmental outcomes assessed after 12 months' corrected age.

\section{Overall completeness and applicability of evidence}

Although re-feeding gastric residuals replaces the partially digested milk and gastrointestinal enzymes and hormones and thus may be beneficial, re-feeding abnormal residuals may result in adverse outcomes such as emesis, NEC, or sepsis. The review identified only one trial with a small sample size. We are uncertain as to the effect of re-feeding gastric residual on any of the outcomes. The quality of evidence is low to very low. Similarly, we are uncertain regarding the effect of re-feeding gastric residual in the subgroups of human milk-fed and formula-fed infants.

All infants recruited to the included trial were between 23 and 28 completed weeks' gestational age, and most infants had a birth weight less than $1000 \mathrm{~g}$. Hence, the results may not be applicable to larger preterm infants, who have a biologically more mature gastrointestinal system and lesser risk of NEC. Furthermore, the volume of gastric residual that is re-fed is equal to the volume of the next feed in the included trial. Hence it is not clear whether refeeding gastric residuals over and above the feed volume is safe.

\section{Quality of the evidence}

The quality of evidence from the only included trial was very low for the outcome of time to regain birth weight (downgraded for attrition and serious imprecision of results), NEC, and/or SIP (downgraded for serious imprecision of results and detection bias) and the number of infants with feed interruption episodes (downgraded for lack of blinding, attrition, and imprecision of the results). The quality of evidence was low for mortality before discharge (downgraded for serious imprecision).

\section{Potential biases in the review process}

We have no financial or other conflicts of interest.

We found only one small trial for inclusion in this review. Although we conducted a comprehensive search, we cannot exclude fully the possibility of publication bias because we do not know whether other published (but not indexed) or unpublished trials have been conducted.

\section{Agreements and disagreements with other studies or reviews}

We are not aware of other systematic reviews on re-feeding versus discarding gastric residuals in preterm infants.

Two studies excluded from this review were RCTs on re-feeding or discarding gastric residuals done in critically ill adult patients who were receiving tube feeds (Booker 2000; Juvé-Udina 2009). One study found a decrease in the incidence and severity of delayed gastric emptying in the re-feeding group (Juvé-Udina 2009). There was no difference in other outcomes such as vomiting, diarrhoea, abdominal distension, or dyselectrolytaemia, although there was an increase in the number of hyperglycaemia episodes in the re-feeding group. These trialists recommended to re-feed gastric residuals in critically ill adult patients, whereas the other study found an increase in complications such as tube clogging, nausea, and diarrhoea in the re-feeding group (Booker 2000). Thus, the results from these two studies are controversial. Moreover, it is difficult to make an inference from adult studies because the biology and pathologies of preterm infants are entirely different.

\section{AUTHORS' CONCLUSIONS}

\section{Implications for practice}

The available evidence is insufficient to support or refute refeeding gastric residuals in preterm infants because the results are imprecise and the quality of evidence is low to very low.

\section{Implications for research}

An RCT adequately powered to detect meaningful differences in outcomes is needed to assess whether re-feeding versus discarding gastric residuals improves important clinical outcomes for preterm infants. This trial should address important aspects of intervention such as the quantity and quality of the gastric residual that is re-fed, and whether the volume of gastric residual that is re-fed is included in or excluded from the volume of the next feed. The randomisation should be stratified for human milk-fed and formula-fed infants, and the effect of additional formula exposure while gastric residual is discarded in formula-fed infants should be assessed. The trial should assess weight, linear and head growth during hospital stay, postdischarge growth, neurodevelopmental outcomes, and risk of potential complications of re-feeding of gastric residuals such as necrotising enterocolitis and sepsis.

\section{ACK N O WLE D GEMENTS}

The methods section of this protocol is based on a standard template used by Cochrane Neonatal. We are grateful to Dr. Ariel Salas for providing additional data from the trial. 


\section{RE F E R E N C E S}

\section{References to studies included in this review}

Salas 2015 \{published and unpublished data\}

Salas AA, Cuna A, Bhat R, McGwin G Jr, Carlo WA, Ambalavanan N. A randomised trial of re-feeding gastric residuals in preterm infants. Archives of Disease in Childhood. Fetal and Neonatal Edition 2015;100(3):F224-8. [DOI: 10.1136/ archdischild-2014-307067; PUBMED: 25552280; PUBMED: 25552280]

\section{References to studies excluded from this review}

Booker 2000 \{published data only\}

Booker KJ, Niedringhaus L, Eden B, Arnold JS. Comparison of 2 methods of managing gastric residual volumes from feeding tubes. American Journal of Critical Care 2000;9(5):318-24. [PUBMED: 10976355]

\section{Juvé-Udina 2009 \{published data only\}}

Juvé-Udina ME, Valls-Miró C, Carreño-Granero A, MartinezEstalella G, Monterde-Prat D, Domingo-Felici CM, et al. To return or to discard? Randomised trial on gastric residual volume management. Intensive \& Critical Care Nursing 2009;25(5):258-67. [DOI: 10.1016/j.iccn.2009.06.004; PUBMED: 19615907]

\section{Additional references}

\section{Abiramalatha 2018}

Abiramalatha T, Thanigainathan S, Ninan B. Routine monitoring of gastric residual for prevention of necrotising enterocolitis in preterm infants. Cochrane Database of Systematic Reviews 2018, Issue 1. [DOI: 10.1002/14651858.CD012937]

\section{Duro 2011}

Duro D, Mitchell PD, Kalish LA, Martin C, McCarthy M, Jaksic T, et al. Risk factors for parenteral nutrition-associated liver disease following surgical therapy for necrotizing enterocolitis: a Glaser Pediatric Research Network Study. Journal of Pediatric Gastroenterology and Nutrition 2011;52(5):595-600 [Erratum in: Journal of Pediatric Gastroenterology and Nutrition 2011;53(5):583]. [DOI: 10.1097/MPG.0b013e31820e8396; PUBMED: 21464752 ]

\section{Dutta 2015}

Dutta S, Singh B, Chessell L, Wilson J, Janes M, McDonald K, et al. Guidelines for feeding very low birth weight infants. Nutrients 2015;7(1):423-42. [DOI: 10.3390/nu7010423; PUBMED: 25580815]

\section{Embleton 2013}

Embleton ND. Early nutrition and later outcomes in preterm infants. World Review of Nutrition and Dietetics 2013;106:26-32. [DOI: 10.1159/000342553; PUBMED: 23428677]

\section{Franz 2009}

Franz AR, Pohlandt F, Bode H, Mihatsch WA, Sander S, Kron M, et al. Intrauterine, early neonatal, and postdischarge growth and neurodevelopmental outcome at 5.4 years in extremely preterm infants after intensive neonatal nutritional support. Pediatrics 2009;123(1):e101-9. [DOI: 10.1542/peds.2008-1352; PUBMED: 19117831]

\section{GRADEpro GDT [Computer program]}

McMaster University (developed by Evidence Prime). GRADEpro GDT. Version accessed 12 September 2017. Hamilton (ON): McMaster University (developed by Evidence Prime), 2014.

\section{Graham 2006}

Graham PL 3rd, Begg MD, Larson E, Della-Latta P, Allen A, Saiman L. Risk factors for late onset gram-negative sepsis in low birth weight infants hospitalized in the neonatal intensive care unit. Pediatric Infectious Disease Journal 2006;25(2):113-7. [DOI: 10.1097/01.inf.0000199310.52875.10; PUBMED: 16462286]

\section{Gregory 2012}

Gregory KE, Connolly TC. Enteral feeding practices in the NICU: results from a 2009 Neonatal Enteral Feeding Survey. Advances in Neonatal Care 2012;12(1):46-55. [DOI: 10.1097/ ANC.0b013e3182425aab; PUBMED: 22301544]

\section{Guillet 2006}

Guillet R, Stoll BJ, Cotten CM, Gantz M, McDonald S, Poole WK, et al. Association of $\mathrm{H} 2$-blocker therapy and higher incidence of necrotizing enterocolitis in very low birth weight infants. Pediatrics 2006;117(2):e137-42. [DOI: 10.1542/peds.2005-1543; PUBMED: 16390920]

\section{Hermansen 2005}

Hermansen MC, Hermansen MG. Intravascular catheter complications in the neonatal intensive care unit. Clinics in Perinatology 2005;32(1):141-56. [DOI: 10.1016/j.clp.2004.11.005; PUBMED: 15777826$]$

\section{Higgins 2017}

Higgins JP, Green S, editor(s). Cochrane Handbook for Systematic Reviews of Interventions Version 5.2.0 (updated June 2017). The Cochrane Collaboration, 2017. Available from handbook.cochrane.org.

\section{Hodges 1993}

Hodges C, Vincent PA. Why do NICU nurses not refeed gastric residuals prior to feeding by gavage?. Neonatal Network 1993;12(8):37-40. [PUBMED: 8121354]

\section{Ittmann 1992}

Ittmann PI, Amarnath R, Berseth CL. Maturation of antroduodenal motor activity in preterm and term infants. Digestive Diseases and Sciences 1992;37(1):14-9. [PUBMED: 1728520]

\section{Kaur 2015}

Kaur A, Kler N, Saluja S, Modi M, Soni A, Thakur A, et al. Abdominal circumference or gastric residual volume as measure of feed intolerance in VLBW infants. Journal of Pediatric Gastroenterology and Nutrition 2015;60(2):259-63. [DOI: 10.1097/MPG.0000000000000576; PUBMED: 25238118] 


\section{Li 2014}

Li YF, Lin HC, Torrazza RM, Parker L, Talaga E, Neu J. Gastric residual evaluation in preterm neonates: a useful monitoring technique or a hindrance?. Pediatrics and Neonatology 2014;55(5):335-40. [DOI: 10.1016/j.pedneo.2014.02.008; PUBMED: 25129325]

\section{Moher 2009}

Moher D, Liberati A, Tetzlaff J, Altman DG, PRISMA Group. Preferred reporting items for systematic reviews and meta-analyses: the PRISMA statement. Journal of Clinical Epidemiology 2009;62(10):1006-12. [PUBMED: 19631508]

\section{Neu 2007}

Neu J. Gastrointestinal maturation and implications for infant feeding. Early Human Development 2007;83(12):767-75. [DOI: 10.1016/j.earlhumdev.2007.09.009; PUBMED: 17913404]

\section{Parker 2015}

Parker L, Torrazza RM, Li Y, Talaga E, Shuster J, Neu J. Aspiration and evaluation of gastric residuals in the neonatal intensive care unit: state of the science. Journal of Perinatal \& Neonatal Nursing 2015;29(1):51-9. [DOI: 10.1097/JPN.0000000000000080; PUBMED: 25633400]

\section{RevMan 2014 [Computer program]}

Nordic Cochrane Centre, The Cochrane Collaboration. Review Manager 5 (RevMan 5). Version 5.3. Copenhagen: Nordic Cochrane Centre, The Cochrane Collaboration, 2014.

\section{CHARACTERISTICS OF STUDIES}

Characteristics of included studies [ordered by study ID]

\section{Riezzo 2000}

Riezzo G, Indrio F, Montagna O, Tripaldi C, Laforgia N, Chiloiro M, et al. Gastric electrical activity and gastric emptying in term and preterm newborns. Neurogastroenterology and Motility 2000;12(3):223-9. [PUBMED: 10867619]

\section{Schünemann 2013}

Schünemann H, Brożek J, Guyatt G, Oxman A, editor(s). Handbook for grading the quality of evidence and the strength of recommendations using the GRADE approach (updated October 2013). GRADE Working Group, 2013. Available from gdt.gradepro.org/app/handbook/handbook.html..

\section{Stevens 2016}

Stevens TP, Shields E, Campbell D, Combs A, Horgan M, La Gamma EF, et al. Variation in enteral feeding practices and growth outcomes among very premature infants: a report from the New York State Perinatal Quality Collaborative. American Journal of Perinatology 2016;33(1):9-19. [DOI: 10.1055/ s-0035-1554794; PUBMED: 26084749]

\section{Walsh 1986}

Walsh MC, Kliegman RM. Necrotizing enterocolitis: treatment based on staging criteria. Pediatric Clinics of North America 1986;33(1):179-201. [PUBMED: 3081865]

\section{Williams 2010}

Williams TA, Leslie GD. Should gastric aspirate be discarded or retained when gastric residual volume is removed from gastric tubes?. Australian Critical Care 2010;23(4):215-7. [DOI: 10.1016/ j.aucc.2010.05.001; PUBMED: 20558081]

\section{Salas 2015}

\begin{tabular}{ll}
\hline Methods & RCT \\
\hline Participants & $\begin{array}{l}72 \text { Infants ( } 36 \text { in each group) with gestational age between } 230 / 7 \text { and } 286 / 7 \text { weeks receiving minimal } \\
\text { enteral nutrition (defined as enteral feeding volume }<24 \mathrm{~mL} / \mathrm{kg} / \mathrm{d} \text { ) and intravenous fluids during the } \\
\text { first week after birth were eligible. Infants with major congenital/chromosomal anomalies and those } \\
\text { considered to have a low likelihood of survival in the opinion of the clinical team were excluded. }\end{array}$
\end{tabular}

Interventions

Gastric residual volume was checked with a syringe before each feeding, with the infant in the supine position. If the gastric residual volume was more than one-third of the previous feeding or $>2 \mathrm{~mL}$, if the clinician's decision was to continue enteral feeding, then:

- Intervention or re-feeding group: gastric residual was re-fed

- Comparison or fresh-feeding group: gastric residual was discarded followed by feeding of fresh human milk or formula

Slightly greenish or dark yellow gastric residuals were re-fed. Gastric residuals containing blood on visual inspection by bedside nurses were not re-fed. Small gastric residual volumes (< one-third of previous feeding volume or $<2 \mathrm{~mL}$ ) were managed according to clinician preference (usually re-fed unless bilious or with blood). When an infant in the re-feeding group had large gastric residual volumes for 3 consecutive feedings, the gastric residual volume before the fourth feeding was discarded and fresh human milk/formula was given. The amount of gastric residual did not influence the amount of 
Salas 2015 (Continued)

feed given at the next feeding. The allocated intervention was continued until full enteral feeding was

achieved and maintained for 2 consecutive days

Primary outcomes
- Time to achieve full enteral feeding (defined as $\geq 120 \mathrm{~mL} / \mathrm{kg} / \mathrm{d}$ ) for 2 consecutive days
- Diagnosis of SIP and/or NEC and/or death between birth and 120 days or discharge, whichever was
earlier
Secondary outcomes
- Number of TPN days
- Time to regain birth weight
- Number of episodes of feeding intolerance (defined as interruption of enteral feeding for $>12$ hours)
- Duration of hospital stay

Notes

Enteral feeding was administered as intermittent bolus gavage feedings every 3 hours. Either expressed human milk (preferred) from the mother or high-protein full-strength preterm formula ( $24 \mathrm{cal} /$ $\mathrm{oz}$ ) was used for feeding. Donor human milk was not used. Feeding advancement was done by $20-\mathrm{mL} /$ $\mathrm{kg} / \mathrm{d}$ increments until the total volume reached $\geq 120 \mathrm{~mL} / \mathrm{kg} / \mathrm{d}$. If human milk is the source of enteral nutrition, human milk fortifier is added once the enteral feeding volume reaches 100 to $120 \mathrm{~mL} / \mathrm{kg} / \mathrm{d}$

\section{Risk of bias}

\begin{tabular}{|c|c|c|}
\hline Bias & Authors' judgement & Support for judgement \\
\hline $\begin{array}{l}\text { Random sequence genera- } \\
\text { tion (selection bias) }\end{array}$ & Low risk & $\begin{array}{l}\text { Participants were randomly assigned to one of the intervention groups follow- } \\
\text { ing simple randomisation procedures }\end{array}$ \\
\hline $\begin{array}{l}\text { Allocation concealment } \\
\text { (selection bias) }\end{array}$ & Low risk & $\begin{array}{l}\text { "using sequentially numbered, opaque, sealed envelopes. Sealed envelopes } \\
\text { were opened in sequential order after informed consent was obtained" }\end{array}$ \\
\hline $\begin{array}{l}\text { Blinding of participants } \\
\text { and personnel (perfor- } \\
\text { mance bias) } \\
\text { All outcomes }\end{array}$ & High risk & The intervention was not masked \\
\hline $\begin{array}{l}\text { Blinding of outcome as- } \\
\text { sessment (detection bias) } \\
\text { All outcomes }\end{array}$ & High risk & The intervention was not masked \\
\hline $\begin{array}{l}\text { Incomplete outcome data } \\
\text { (attrition bias) } \\
\text { All outcomes }\end{array}$ & Low risk & $\begin{array}{l}\text { All } 72 \text { infants were taken into account for the outcomes of mortality before dis- } \\
\text { charge and NEC. The babies who had developed NEC or died were excluded } \\
\text { from the analysis for all other outcomes }\end{array}$ \\
\hline $\begin{array}{l}\text { Selective reporting (re- } \\
\text { porting bias) }\end{array}$ & Low risk & Study protocol had been published. All proposed outcomes were reported \\
\hline Other bias & Low risk & Nil \\
\hline
\end{tabular}

NEC: necrotising enterocolitis.

$\mathrm{RCT}$ : randomised controlled trial.

SIP: spontaneous intestinal perforation.

TPN: total parenteral nutrition.

Characteristics of excluded studies [ordered by study ID] 


\begin{tabular}{ll}
\hline Study & Reason for exclusion \\
\hline Booker 2000 & The RCT was done in critically ill adult patients. \\
\hline Juvé-Udina 2009 & The RCT was done in critically ill adult patients. \\
\hline
\end{tabular}

RCT: randomised controlled trial.

\section{DATA AND ANALYSES}

Comparison 1. Re-feeding versus discarding gastric residual

\begin{tabular}{|c|c|c|c|c|}
\hline Outcome or subgroup title & $\begin{array}{l}\text { No. of } \\
\text { studies }\end{array}$ & $\begin{array}{l}\text { No. of } \\
\text { partici- } \\
\text { pants }\end{array}$ & Statistical method & Effect size \\
\hline 1 Time to regain birth weight (days) & 1 & & $\begin{array}{l}\text { Mean Difference (IV, Fixed, } \\
95 \% \mathrm{CI})\end{array}$ & Subtotals only \\
\hline 1.1 All Infants & 1 & 59 & $\begin{array}{l}\text { Mean Difference (IV, Fixed, } \\
95 \% \mathrm{CI})\end{array}$ & $0.40[-2.89,3.69]$ \\
\hline 1.2 Infants fed only human milk & 1 & 41 & $\begin{array}{l}\text { Mean Difference (IV, Fixed, } \\
95 \% \mathrm{Cl})\end{array}$ & $-1.80[-5.51,1.91]$ \\
\hline 1.3 Infants fed formula milk & 1 & 18 & $\begin{array}{l}\text { Mean Difference (IV, Fixed, } \\
95 \% \mathrm{Cl})\end{array}$ & $3.0[-4.03,10.03]$ \\
\hline $\begin{array}{l}2 \text { Number of Infants with NEC stage } 2 \text { or } 3 \\
\text { and/or SIP }\end{array}$ & 1 & & $\begin{array}{l}\text { Risk Ratio (M-H, Fixed, 95\% } \\
\mathrm{Cl})\end{array}$ & Subtotals only \\
\hline 2.1 All Infants & 1 & 72 & $\begin{array}{l}\text { Risk Ratio (M-H, Fixed, 95\% } \\
\mathrm{Cl})\end{array}$ & $0.71[0.25,2.04]$ \\
\hline 2.2 Infants fed only human milk & 1 & 49 & $\begin{array}{l}\text { Risk Ratio (M-H, Fixed, 95\% } \\
\mathrm{Cl})\end{array}$ & $0.96[0.06,14.50]$ \\
\hline 2.3 Infants fed formula milk & 1 & 22 & $\begin{array}{l}\text { Risk Ratio (M-H, Fixed, 95\% } \\
\mathrm{Cl})\end{array}$ & $0.8[0.29,2.21]$ \\
\hline $\begin{array}{l}3 \text { Time to reach full enteral feeds }(120 \mathrm{~mL} / \mathrm{kg} / \\
\text { d) }\end{array}$ & 1 & & $\begin{array}{l}\text { Mean Difference (IV, Fixed, } \\
95 \% \mathrm{CI})\end{array}$ & Subtotals only \\
\hline 3.1 All Infants & 1 & 59 & $\begin{array}{l}\text { Mean Difference (IV, Fixed, } \\
95 \% \mathrm{Cl})\end{array}$ & $-1.30[-2.93,0.33]$ \\
\hline 3.2 Infants fed only human milk & 1 & 41 & $\begin{array}{l}\text { Mean Difference (IV, Fixed, } \\
95 \% \mathrm{Cl})\end{array}$ & $-0.60[-2.90,1.70]$ \\
\hline 3.3 Infants fed formula milk & 1 & 18 & $\begin{array}{l}\text { Mean Difference (IV, Fixed, } \\
95 \% \mathrm{Cl})\end{array}$ & $-1.90[-5.50,1.70]$ \\
\hline $\begin{array}{l}4 \text { Number of infants with episodes of inter- } \\
\text { ruption of feeds } \geq 12 \text { hours }\end{array}$ & 1 & & $\begin{array}{l}\text { Risk Ratio (M-H, Fixed, 95\% } \\
\mathrm{Cl} \text { ) }\end{array}$ & Subtotals only \\
\hline
\end{tabular}




\begin{tabular}{|c|c|c|c|c|}
\hline Outcome or subgroup title & $\begin{array}{l}\text { No. of } \\
\text { studies }\end{array}$ & $\begin{array}{l}\text { No. of } \\
\text { partici- } \\
\text { pants }\end{array}$ & Statistical method & Effect size \\
\hline 4.1 All infants & 1 & 59 & $\begin{array}{l}\text { Risk Ratio (M-H, Fixed, 95\% } \\
\mathrm{Cl} \text { ) }\end{array}$ & $0.80[0.42,1.52]$ \\
\hline 4.2 Infants fed only human milk & 1 & 41 & $\begin{array}{l}\text { Risk Ratio (M-H, Fixed, 95\% } \\
\mathrm{Cl} \text { ) }\end{array}$ & $1.05[0.45,2.46]$ \\
\hline 4.3 Infants fed formula milk & 1 & 18 & $\begin{array}{l}\text { Risk Ratio (M-H, Fixed, 95\% } \\
\mathrm{Cl} \text { ) }\end{array}$ & $0.5[0.18,1.40]$ \\
\hline $\begin{array}{l}5 \text { Number of infants with weight }<10 \text { th per- } \\
\text { centile at discharge }\end{array}$ & 1 & & $\begin{array}{l}\text { Risk Ratio (M-H, Fixed, 95\% } \\
\mathrm{CI})\end{array}$ & Subtotals only \\
\hline 5.1 All infants & 1 & 59 & $\begin{array}{l}\text { Risk Ratio (M-H, Fixed, 95\% } \\
\mathrm{Cl} \text { ) }\end{array}$ & $1.29[0.38,4.34]$ \\
\hline 5.2 Infants fed only human milk & 1 & 41 & $\begin{array}{l}\text { Risk Ratio (M-H, Fixed, 95\% } \\
\mathrm{Cl})\end{array}$ & $1.58[0.29,8.46]$ \\
\hline 5.3 Infants fed formula milk & 1 & 18 & $\begin{array}{l}\text { Risk Ratio (M-H, Fixed, 95\% } \\
\mathrm{CI})\end{array}$ & $1.0[0.18,5.63]$ \\
\hline 6 Number of TPN days & 1 & & $\begin{array}{l}\text { Mean Difference (IV, Fixed, } \\
95 \% \mathrm{CI} \text { ) }\end{array}$ & Subtotals only \\
\hline 6.1 All infants & 1 & 59 & $\begin{array}{l}\text { Mean Difference (IV, Fixed, } \\
95 \% \mathrm{CI})\end{array}$ & $-0.30[-2.07,1.47]$ \\
\hline 6.2 Infants fed only human milk & 1 & 41 & $\begin{array}{l}\text { Mean Difference (IV, Fixed, } \\
95 \% \mathrm{CI} \text { ) }\end{array}$ & $0.20[-2.15,2.55]$ \\
\hline 6.3 Infants fed formula milk & 1 & 18 & $\begin{array}{l}\text { Mean Difference (IV, Fixed, } \\
95 \% \mathrm{CI})\end{array}$ & $-1.20[-5.04,2.64]$ \\
\hline 7 Mortality before discharge & 1 & & $\begin{array}{l}\text { Risk Ratio (M-H, Fixed, 95\% } \\
\mathrm{Cl})\end{array}$ & Subtotals only \\
\hline 7.1 All infants & 1 & 72 & $\begin{array}{l}\text { Risk Ratio (M-H, Fixed, 95\% } \\
\mathrm{Cl})\end{array}$ & $0.5[0.14,1.85]$ \\
\hline 7.2 Infants fed only human milk & 1 & 49 & $\begin{array}{l}\text { Risk Ratio (M-H, Fixed, 95\% } \\
\mathrm{Cl} \text { ) }\end{array}$ & $0.64[0.12,3.50]$ \\
\hline 7.3 Infants fed formula milk & 1 & 22 & $\begin{array}{l}\text { Risk Ratio (M-H, Fixed, 95\% } \\
\mathrm{Cl} \text { ) }\end{array}$ & $0.33[0.04,2.73]$ \\
\hline 8 Duration of hospital stay (days) & 1 & & $\begin{array}{l}\text { Mean Difference (IV, Fixed, } \\
95 \% \mathrm{CI} \text { ) }\end{array}$ & Subtotals only \\
\hline 8.1 All infants & 1 & 59 & $\begin{array}{l}\text { Mean Difference (IV, Fixed, } \\
95 \% \mathrm{CI})\end{array}$ & $-1.90[-25.27,21.47]$ \\
\hline 8.2 Infants fed only human milk & 1 & 41 & $\begin{array}{l}\text { Mean Difference (IV, Fixed, } \\
95 \% \mathrm{CI} \text { ) }\end{array}$ & $-10.00[-37.97,13.97]$ \\
\hline
\end{tabular}




\begin{tabular}{lllll}
\hline Outcome or subgroup title & $\begin{array}{l}\text { No. of } \\
\text { studies }\end{array}$ & $\begin{array}{l}\text { No. of } \\
\text { partici- } \\
\text { pants }\end{array}$ & Statistical method & Effect size \\
\hline 8.3 Infants fed formula milk & 1 & 18 & $\begin{array}{l}\text { Mean Difference (IV, Fixed, } \\
95 \% \mathrm{Cl})\end{array}$ & $51.0[-8.61,110.61]$ \\
\hline
\end{tabular}

Analysis 1.1. Comparison 1 Re-feeding versus discarding gastric residual, Outcome 1 Time to regain birth weight (days).

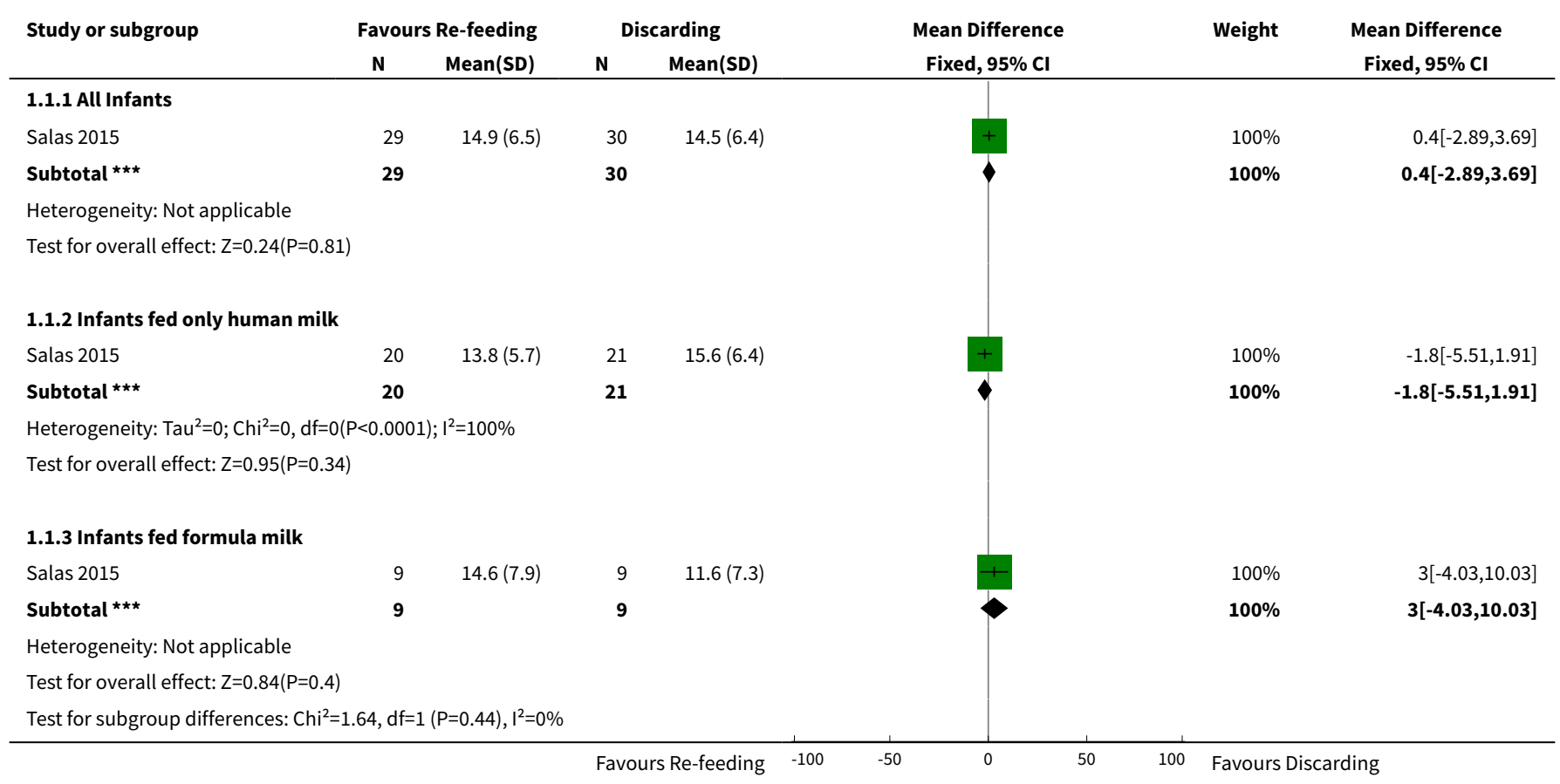

Analysis 1.2. Comparison 1 Re-feeding versus discarding gastric residual, Outcome 2 Number of Infants with NEC stage 2 or 3 and/or SIP.

\begin{tabular}{|c|c|c|c|c|c|}
\hline Study or subgroup & $\begin{array}{c}\text { Favours } \\
\text { Re-feeding } \\
n / N\end{array}$ & $\begin{array}{c}\text { Favours } \\
\text { Discarding } \\
\mathbf{n} / \mathbf{N} \\
\end{array}$ & $\begin{array}{c}\text { Risk Ratio } \\
\text { M-H, Fixed, 95\% Cl }\end{array}$ & Weight & $\begin{array}{c}\text { Risk Ratio } \\
\text { M-H, Fixed, } 95 \% \text { Cl }\end{array}$ \\
\hline \multicolumn{6}{|l|}{ 1.2.1 All Infants } \\
\hline Salas 2015 & $5 / 36$ & $7 / 36$ & & $100 \%$ & $0.71[0.25,2.04]$ \\
\hline Subtotal $(95 \% \mathrm{CI})$ & 36 & 36 & & $100 \%$ & $0.71[0.25,2.04]$ \\
\hline \multicolumn{6}{|c|}{ Total events: 5 (Favours Re-feeding), 7 (Favours Discarding) } \\
\hline \multicolumn{6}{|c|}{ Test for overall effect: $Z=0.63(P=0.53)$} \\
\hline \multicolumn{6}{|c|}{ 1.2.2 Infants fed only human milk } \\
\hline Salas 2015 & $1 / 25$ & $1 / 24$ & & $100 \%$ & $0.96[0.06,14.5]$ \\
\hline Subtotal $(95 \% \mathrm{Cl})$ & 25 & 24 & & $100 \%$ & $0.96[0.06,14.5]$ \\
\hline Total events: 1 (Favo & (Favours Discard & & & & \\
\hline
\end{tabular}




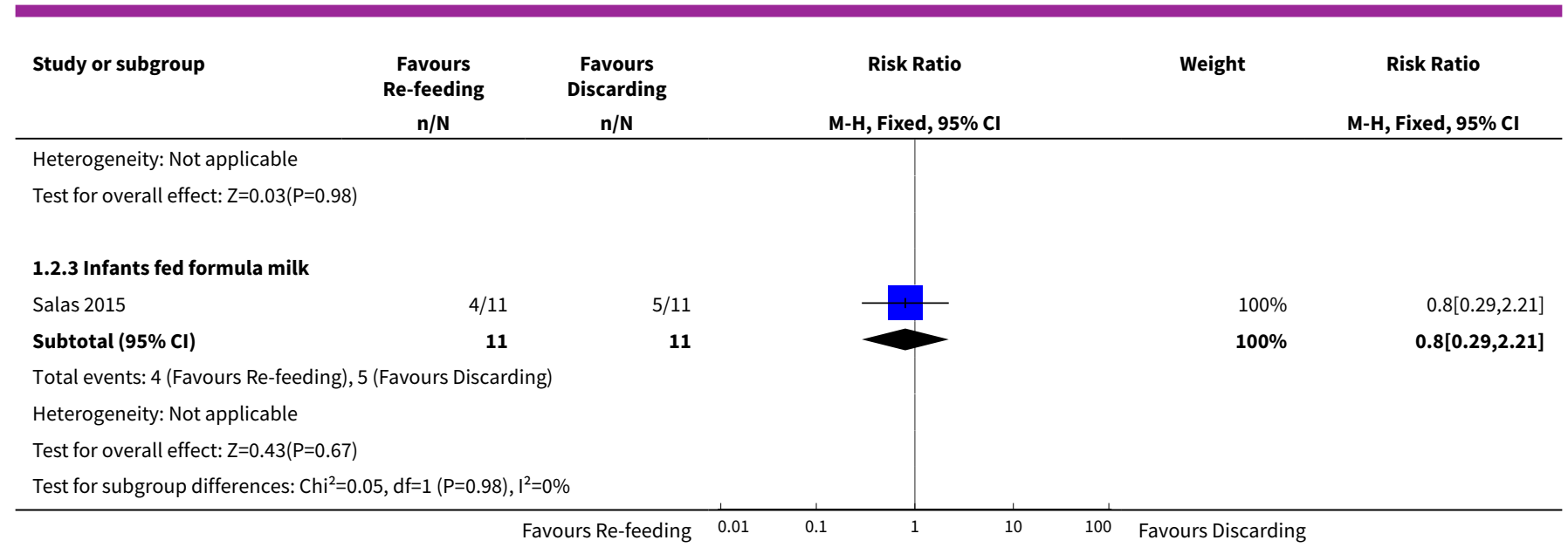

Analysis 1.3. Comparison 1 Re-feeding versus discarding gastric residual, Outcome 3 Time to reach full enteral feeds $(120 \mathrm{~mL} / \mathrm{kg} / \mathrm{d})$.

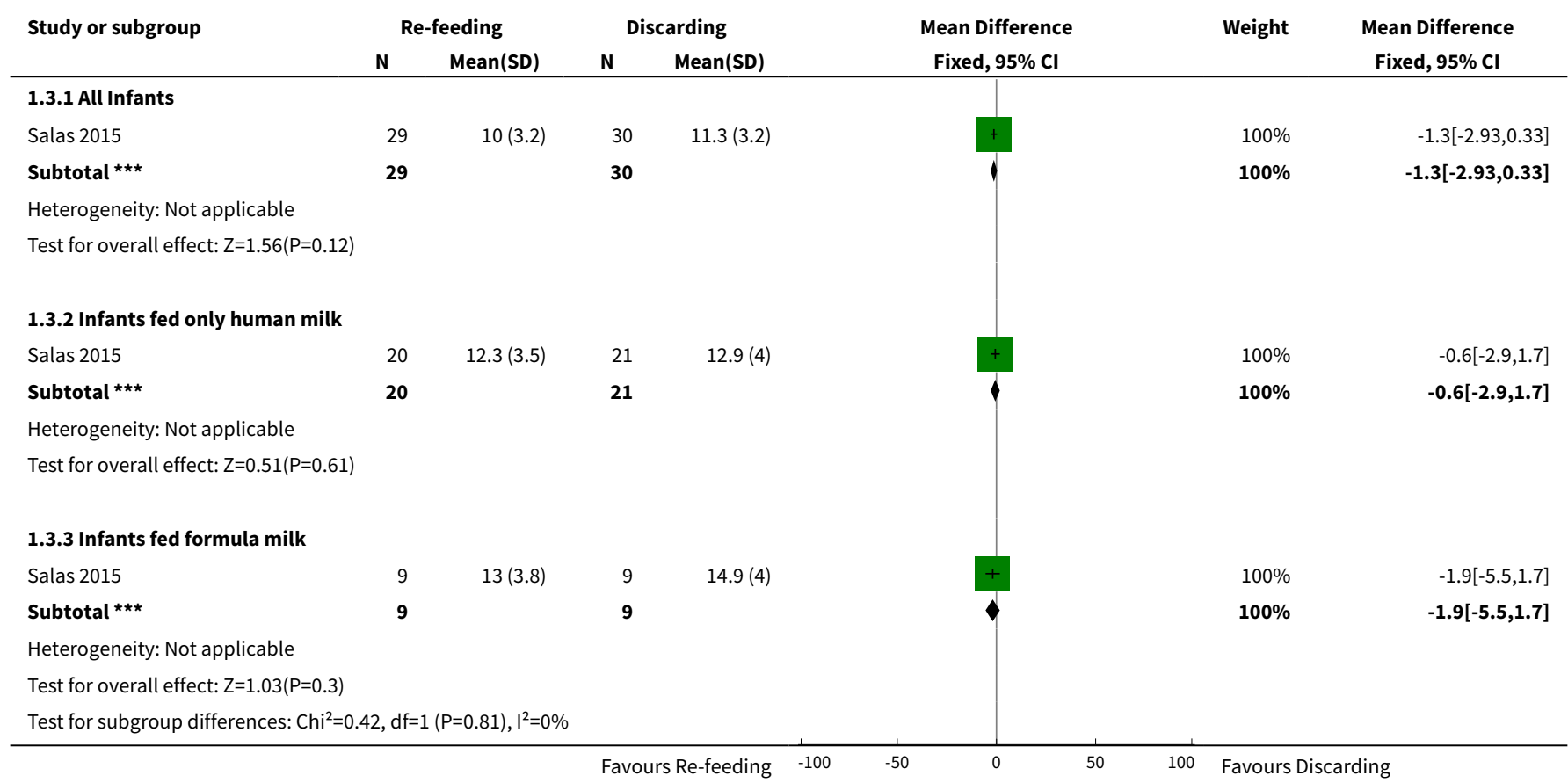

Analysis 1.4. Comparison 1 Re-feeding versus discarding gastric residual, Outcome 4 Number of infants with episodes of interruption of feeds $\geq 12$ hours.

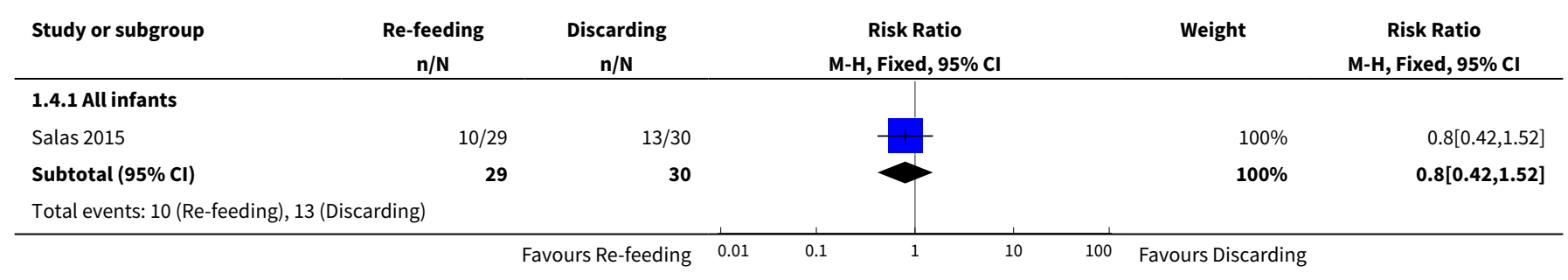




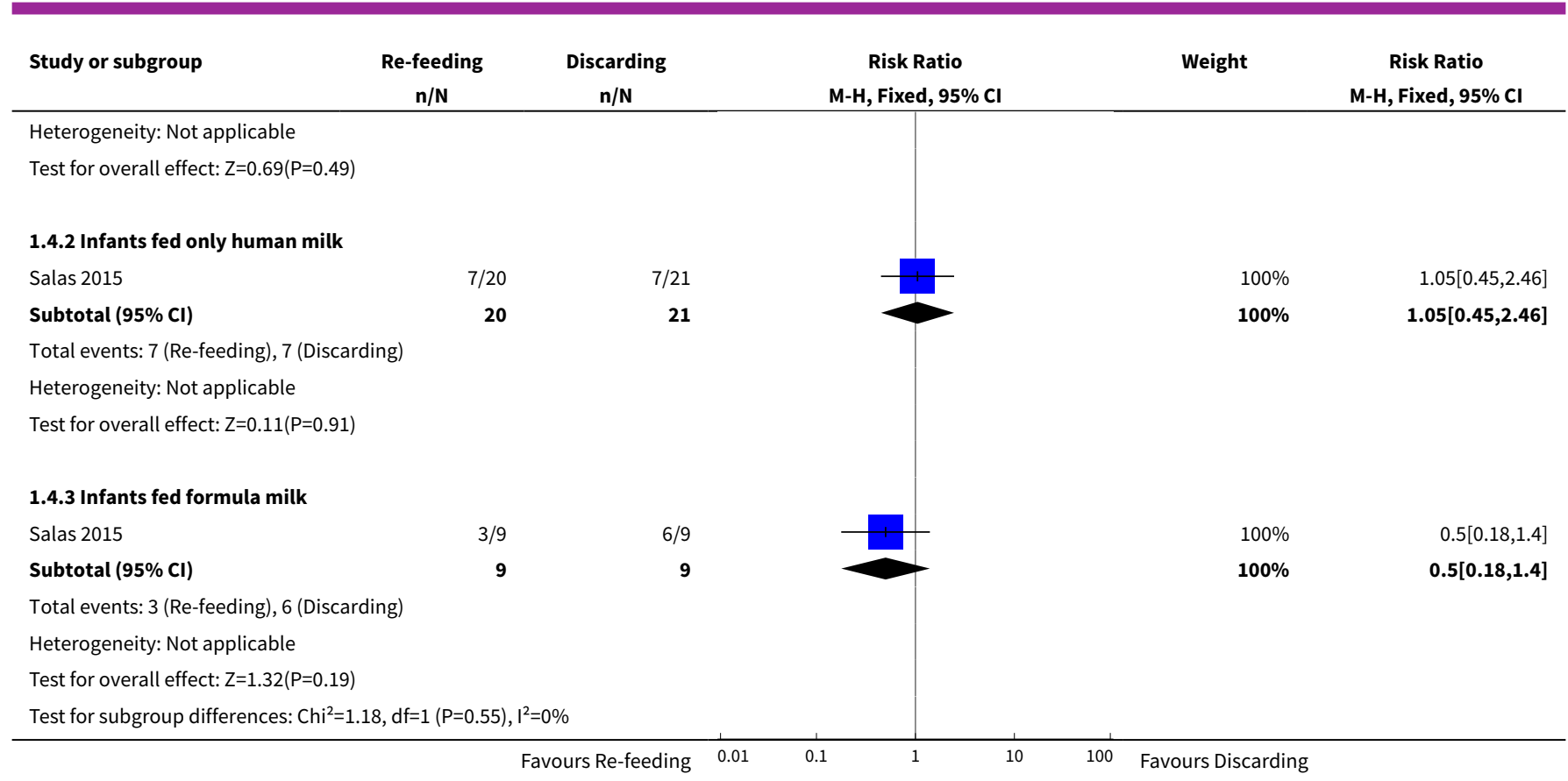

Analysis 1.5. Comparison 1 Re-feeding versus discarding gastric residual, Outcome 5 Number of infants with weight $<10$ th percentile at discharge.

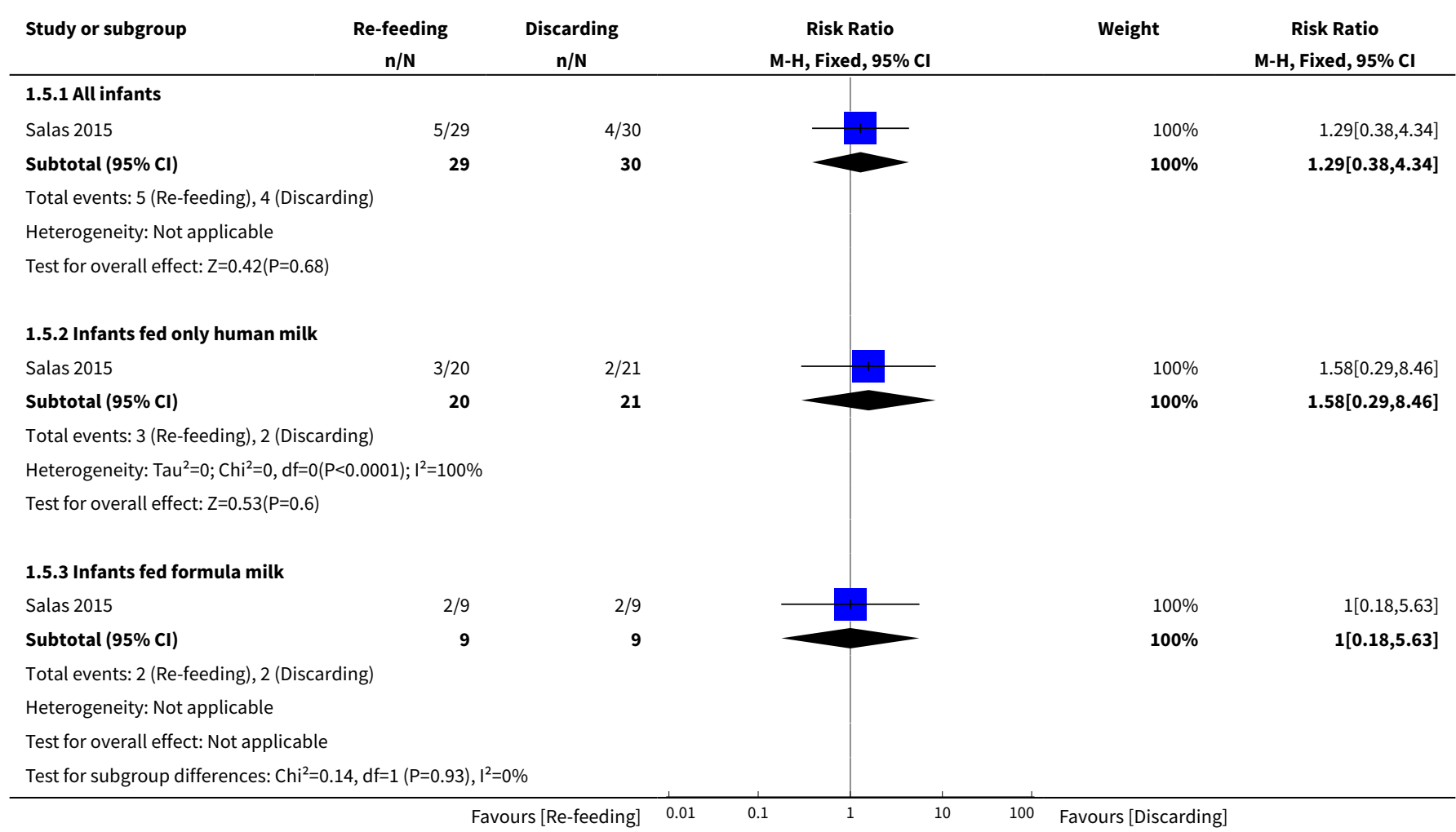


Analysis 1.6. Comparison 1 Re-feeding versus discarding gastric residual, Outcome 6 Number of TPN days.

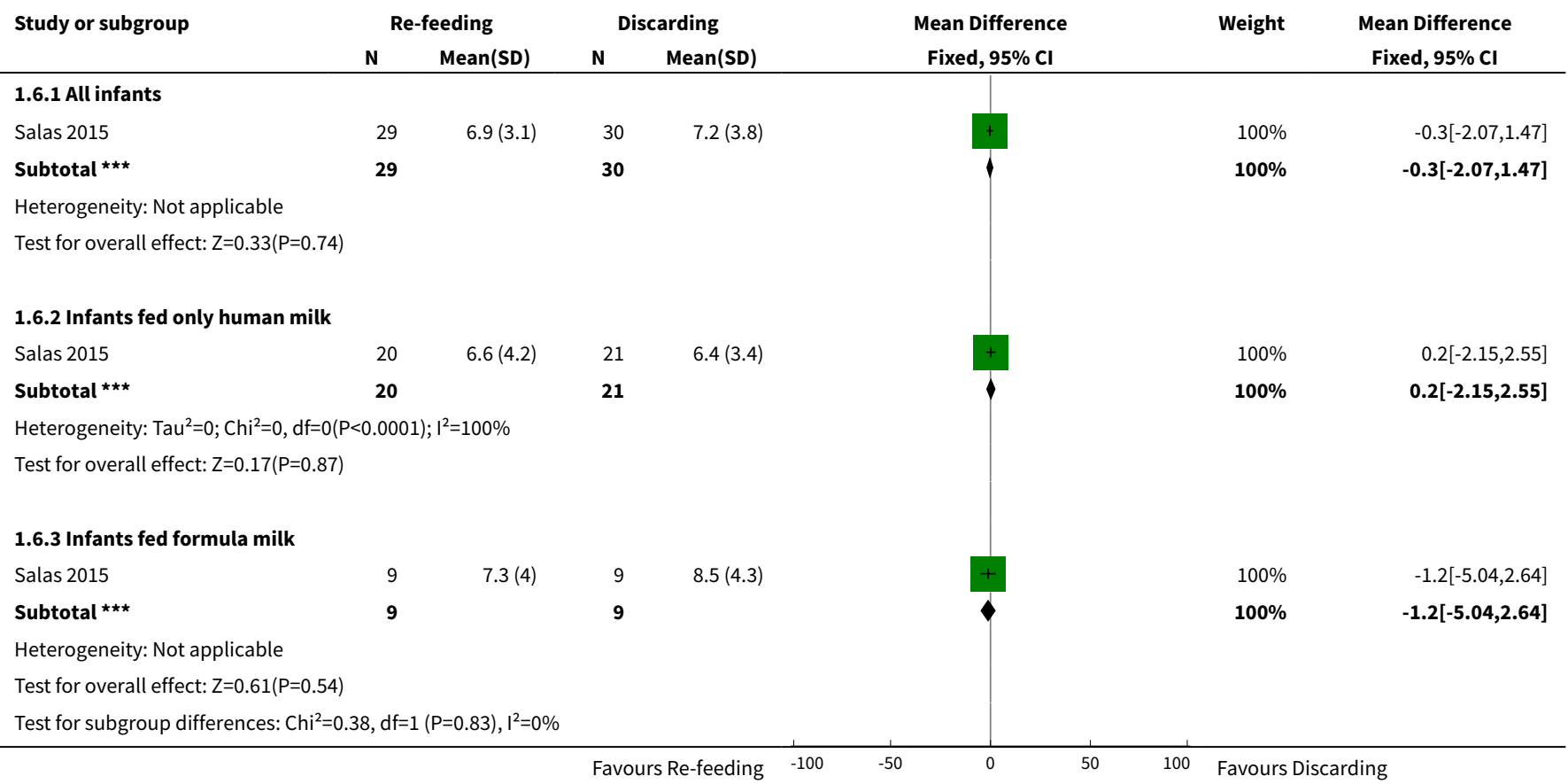

Analysis 1.7. Comparison 1 Re-feeding versus discarding gastric residual, Outcome 7 Mortality before discharge.

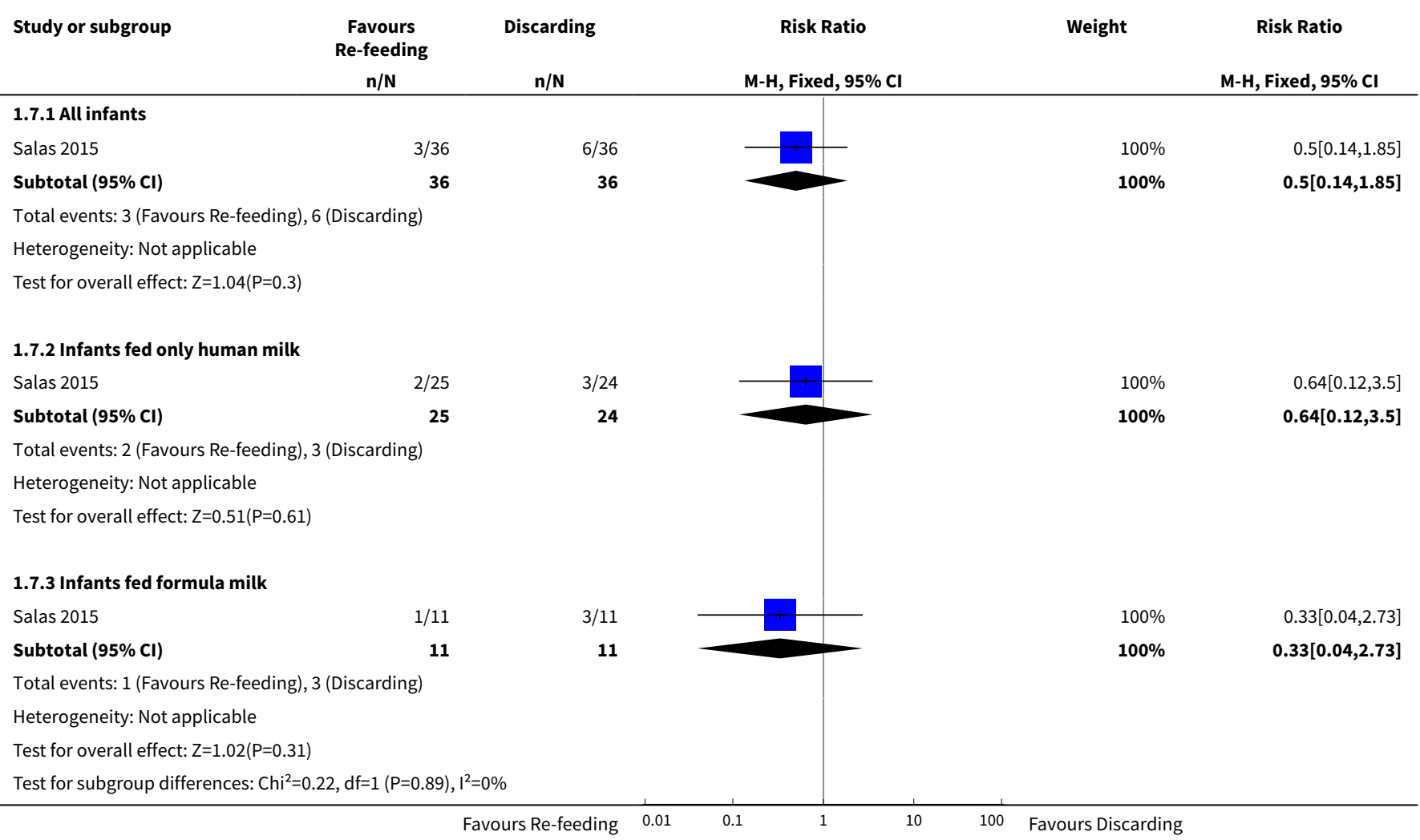


Analysis 1.8. Comparison 1 Re-feeding versus discarding gastric residual, Outcome 8 Duration of hospital stay (days).

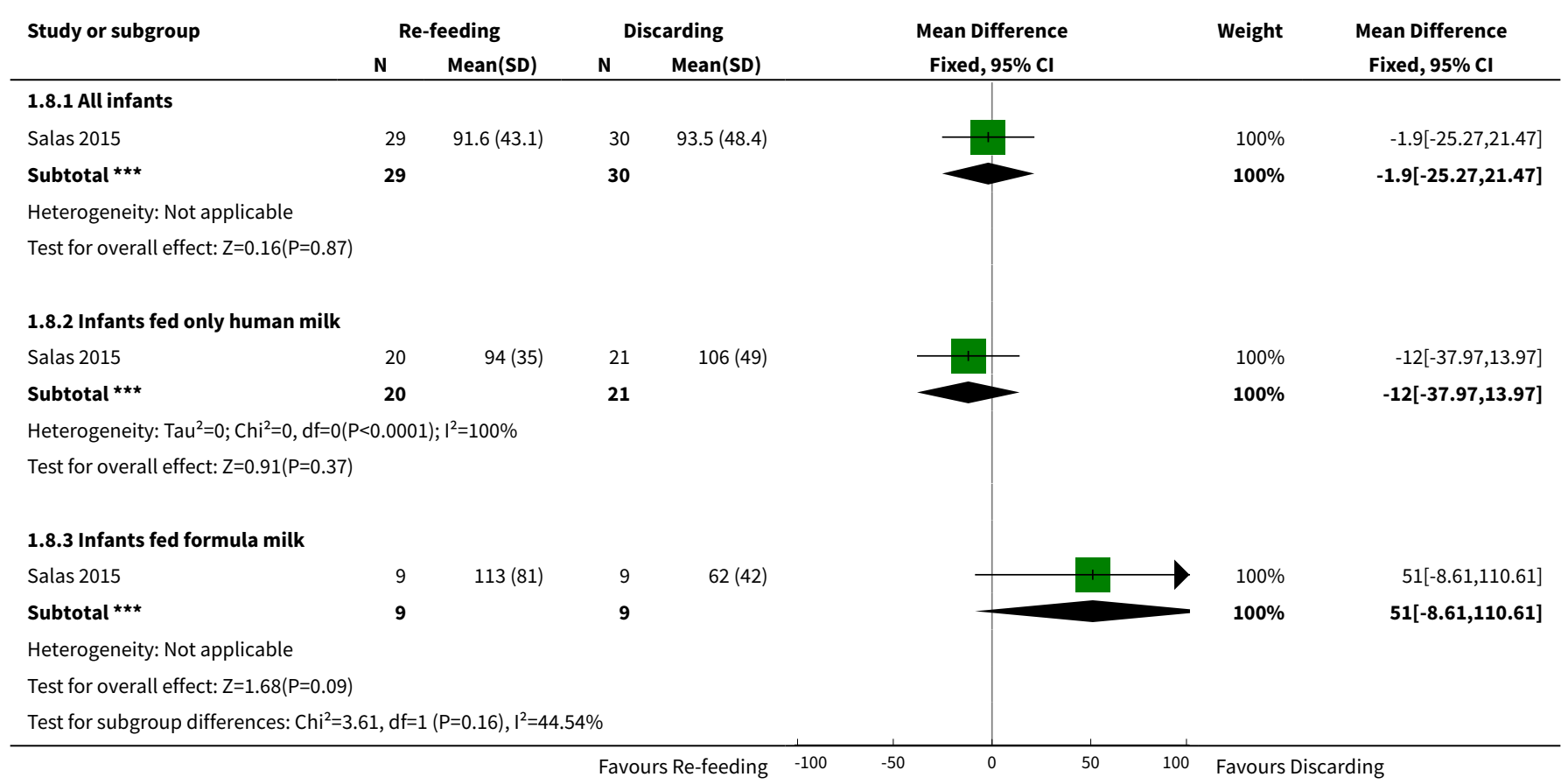

\section{AP PEN DICES}

\section{Appendix 1. Cochrane Neonatal standard search strategy}

PubMed: ((infant, newborn[MeSH] OR newborn OR neonate OR neonatal OR premature OR low birth weight OR VLBW OR LBW or infan* or neonat*) AND (randomized controlled trial [pt] OR controlled clinical trial [pt] OR randomized [tiab] OR placebo [tiab] OR drug therapy [sh] OR randomly [tiab] OR trial [tiab] OR groups [tiab]) NOT (animals [mh] NOT humans [mh]))

Embase: ((exp infant) OR (infan* OR newborn or neonat* OR premature or very low birth weight or low birth weight or VLBW or LBW).mp AND (human not animal) AND (randomized controlled trial or controlled clinical trial or randomized or placebo or clinical trials as topic or randomly or trial or clinical trial).mp

CINAHL: (infan* OR newborn OR neonat* OR premature OR low birth weight OR VLBW OR LBW) AND (randomized controlled trial OR controlled clinical trial OR randomized OR placebo OR clinical trials as topic OR randomly OR trial OR PT clinical trial)

CRS Web: (infan* or newborn or neonat* or premature or preterm or very low birth weight or low birth weight or VLBW or LBW)

\section{Appendix 2. 'Risk of bias' tool}

\section{Sequence generation (checking for possible selection bias). Was the allocation sequence adequately generated?}

For each included study, we categorised the method used to generate the allocation sequence as:

- low risk (any truly random process, e.g. random number table; computer random number generator);

- high risk (any non-random process, e.g. odd or even date of birth; hospital or clinic record number); or

- unclear risk.

\section{Allocation concealment (checking for possible selection bias). Was allocation adequately concealed?}

For each included study, we categorised the method used to conceal the allocation sequence as:

- low risk (e.g. telephone or central randomisation; consecutively numbered sealed opaque envelopes); 
- high risk (e.g. open random allocation; unsealed or non-opaque envelopes, alternation; date of birth); or

- unclear risk.

3. Blinding of participants and personnel (checking for possible performance bias). Was knowledge of the allocated intervention adequately prevented during the study?

For each included study, we categorised the methods used to blind study participants and personnel from knowledge of which intervention a participant received. Blinding was assessed separately for different outcomes or classes of outcomes. We categorised the methods as:

- low risk, high risk, or unclear risk for participants; and

- low risk, high risk, or unclear risk for personnel.

4. Blinding of outcome assessment (checking for possible detection bias). Was knowledge of the allocated intervention adequately prevented at the time of outcome assessment?

For each included study, we categorised the methods used to blind outcome assessment. Blinding was assessed separately for different outcomes or classes of outcomes. We categorised the methods as:

- low risk for outcome assessors;

- high risk for outcome assessors; or

- unclear risk for outcome assessors.

5. Incomplete outcome data (checking for possible attrition bias through withdrawals, dropouts, protocol deviations). Were incomplete outcome data adequately addressed?

For each included study and for each outcome, we described the completeness of data including attrition and exclusions from the analysis. We noted whether attrition and exclusions were reported, the numbers included in the analysis at each stage (compared with the total randomised participants), reasons for attrition or exclusion where reported, and whether missing data were balanced across groups or were related to outcomes. Where sufficient information was reported or supplied by the trial authors, we re-included missing data in the analyses. We categorised the methods as:

- low risk (<20\% missing data);

- high risk ( $\geq 20 \%$ missing data); or

- unclear risk.

\section{Selective reporting bias. Are reports of the study free of the suggestion of selective outcome reporting?}

For each included study, we described how we investigated the possibility of selective outcome reporting bias and what we found. For studies in which study protocols were published in advance, we compared prespecified outcomes versus outcomes eventually reported in the published results. If the study protocol was not published in advance, we contacted study authors to gain access to the study protocol. We assessed the methods as:

- low risk (where it is clear that all of the study's prespecified outcomes and all expected outcomes of interest to the review have been reported);

- high risk (where not all of the study's prespecified outcomes have been reported; one or more reported primary outcomes were not prespecified outcomes of interest and are reported incompletely and so cannot be used; or the study fails to include results of a key outcome that would have been expected to have been reported); or

- unclear risk.

\section{Other sources of bias. Was the study apparently free of other problems that could put it at high risk of bias?}

For each included study, we described any important concerns we had about other possible sources of bias (e.g. whether there was a potential source of bias related to the specific study design, whether the trial was stopped early due to some data-dependent process). We assessed whether each study was free of other problems that could put it at risk of bias as:

- low risk;

- high risk; or

- unclear risk.

If needed, we explored the impact of the level of bias through undertaking sensitivity analyses. 


\section{CONTRIBUTIONS OF AUTHORS}

TA and ST developed the protocol. TA and ST screened search outputs, assessed study eligibility, and extracted and synthesised data. TA and ST assessed risk of bias across key domains and undertook GRADE assessment. All review authors revised the final review.

\section{DECLARATIONS OF INTEREST}

TA has no interest to declare.

ST has no interest to declare.

UB has no interest to declare.

\section{SOURCES OF SUPPORT}

\section{Internal sources}

- Sri Ramachandra Medical College and Research Institute, Porur, Chennai, India.

- Christian Medical College, Vellore, India.

\section{External sources}

- National Institute for Health Research, UK.

Editorial support for Cochrane Neonatal has been funded with funds from a UK National Institute of Health Research (NIHR) Cochrane Programme Grant (16/114/03). The views expressed in this publication are those of the authors and not necessarily those of the National Health Service, the NIHR, or the UK Department of Health.

- Vermont Oxford Network, USA.

Cochrane Neonatal Reviews are produced with support from Vermont Oxford Network, a worldwide collaboration of health professionals dedicated to providing evidence-based care of the highest quality for newborn infants and the highest quality for newborn infants and their families.

\section{DIFFERENCES BETWEEN PROTOCOLANDREVIEW}

For the outcome of time to reach full enteral feeds, we defined full enteral feeds as $\geq 150 \mathrm{~mL} / \mathrm{kg} / \mathrm{d}$ in the protocol. However, in the only included trial, trialists defined it as $\geq 120 \mathrm{~mL} / \mathrm{kg} / \mathrm{d}$ (Salas 2015).

For the outcome of NEC, we planned to include only NEC stage 2 or 3 as per modified Bell's staging. However, trialists of the only included trial defined it as NEC stage 2 or 3 and/or SIP (Salas 2015).

For another outcome, although we planned to analyse the number of episodes of feed interruption lasting $\geq 12$ hours in each group, trialists of the included trial reported the number of infants with episodes of feed interruption lasting $\geq 12$ hours (Salas 2015).

In the protocol, we did not prespecify outcomes for the 'Summary of findings table'.

\section{INDEX TERMS}

\section{Medical Subject Headings (MeSH)}

${ }^{\star}$ Digestion; ${ }^{*}$ Gastrointestinal Contents; Infant Nutritional Physiological Phenomena [ ${ }^{\star}$ physiology]; Infant, Premature [ ${ }^{\star}$ growth \& development]; Randomized Controlled Trials as Topic

\section{MeSH check words}

Humans; Infant, Newborn 